\title{
Synthesis and properties of magnetic
} nanotheranostics coated with polyethylene glycol/
5-fluorouracil/layered double hydroxide

This article was published in the following Dove Press journal: International Journal of Nanomedicine

\author{
Mona Ebadi ${ }^{1}$ \\ Bullo Saifullah ${ }^{1,2}$ \\ Kalaivani Buskaran ${ }^{2}$ \\ Mohd Zobir Hussein ' \\ Sharida Fakurazi ${ }^{3}$ \\ 'Materials Synthesis and Characterization \\ Laboratory, Institute of Advanced \\ Technology (ITMA), Universiti Putra \\ Malaysia, Serdang, Selangor 43400 , \\ Malaysia; ${ }^{2}$ Laboratory for Vaccine and \\ Immunotherapeutic, Institute of \\ Biosciences, Universiti Putra Malaysia, \\ Serdang, Selangor 43400, Malaysia; \\ ${ }^{3}$ Department of Human Anatomy, Faculty \\ of Medicine and Health Sciences, \\ Universiti Putra Malaysia, Serdang, \\ Selangor 43400, Malaysia
}

Background: Cancer treatments are being continually developed. Increasingly more effective and better-targeted treatments are available. As treatment has developed, the outcomes have improved. Purpose: In this work, polyethylene glycol (PEG), layered double hydroxide (LDH) and 5fluorouracil (5-FU) were used as a stabilizing agent, a carrier and an anticancer active agent, respectively.

Characterization and methods: Magnetite nanoparticles ( $\mathrm{Fe} 3 \mathrm{O} 4)$ coated with polyethylene glycol (PEG) and co-coated with 5-fluorouracil/Mg/Al- or $\mathrm{Zn} / \mathrm{Al}$-layered double hydroxide were synthesized by co-precipitation technique. Structural, magnetic properties, particle shape, particle size and drug loading percentage of the magnetic nanoparticles were investigated by XRD, TGA, FTIR, DLS, FESEM, TEM, VSM, UV-vis spectroscopy and HPLC techniques.

Results: XRD, TGA and FTIR studies confirmed the formation of $\mathrm{Fe} 3 \mathrm{O} 4$ phase and the presence of iron oxide nanoparticles, polyethylene glycol, LDH and the drug for all the synthesized samples. The size of the nanoparticles co-coated with $\mathrm{Mg} / \mathrm{Al}-\mathrm{LDH}$ is about $27 \mathrm{~nm}$ compared to $40 \mathrm{~nm}$ when they were co-coated with $\mathrm{Zn} / \mathrm{Al}-\mathrm{LDH}$, with both showings near uniform spherical shape. The iron oxide nanoparticles retain their superparamagnetic property when they were coated with polyethylene glycol, polyethylene glycol co-coated with $\mathrm{Mg} / \mathrm{Al}-$ LDH and polyethylene glycol co-coated with $\mathrm{Zn} / \mathrm{Al}-\mathrm{LDH}$ with magnetic saturation value of 56, 40 and $27 \mathrm{emu} / \mathrm{g}$, respectively. The cytotoxicity study reveals that the anticancer nanodelivery system has better anticancer activity than the free drug, 5-FU against liver cancer HepG2 cells and at the same time, it was found to be less toxic to the normal fibroblast $3 \mathrm{~T} 3$ cells.

Conclusion: These are unique core-shell nanoparticles synthesized with the presence of multiple functionalities are hoped can be used as a multifunctional nanocarrier with the capability of targeted delivery using an external magnetic field and can also be exploited as hypothermia for cancer cells in addition to the chemotherapy property.

Keywords: nano drug delivery, layered double hydroxide, core-shell nanoparticles, iron oxide nanoparticles, 5-fluorouracil

\section{Introduction}

Cancer is caused by cells mutation in the human body and the mutated cells reproduce at a higher rate than the healthy cells. ${ }^{1-3}$ There is a variety of approaches to control cancer disease including surgery, ${ }^{4,5}$ hormone therapy, immunotherapy ${ }^{6-8}$ and radiation therapy or a combination thereof. ${ }^{9}$ However, these common therapies posed some disadvantages such as patient inconvenience (pain), the disappearance of healthy cells, long-term treatment and high expenditure. ${ }^{9,10}$ One of the ways to
Correspondence: Mohd Zobir Hussein Materials Synthesis and Characterization Laboratory, Institute of Advanced Technology (ITMA), Universiti Putra Malaysia, Serdang, Selangor 43400, Malaysia

Tel +60 389468092

Email mzobir@upm.edu.my 
treat cancer or its temporary relief is to use certain medications known as chemotherapy. ${ }^{10,11}$

The chemotherapy is to specifically eliminate or destroy cancer cells by chemical drugs without damaging adjacent and healthy tissues. ${ }^{12,13}$ The development of targeted drug delivery methods using nanotechnology platform through the use of nanoparticles has emerged able to help cancer diagnosis and treatment. ${ }^{4,14}$ Magnetic nanoparticles have great potential for both cancer diagnosis and treatment. ${ }^{5,7,15}$ They have been used as contrast factors in the magnetic resonance imaging (MRI) as well as the nanocarrier in modern drug delivery systems. ${ }^{16-18}$ In recent years, the targeted transfer of chemotherapeutic agents to cancer cells by magnetic nanoparticles has been studied and researched by many scholars and have yielded valuable and desirable results. ${ }^{19}$ Nanotechnology-based drug delivery systems (DDS) have dramatically improved drug therapies due to modification of drug properties, ${ }^{20-22}$ increased drug bioavailability in the bloodstream, ${ }^{23}$ reduced toxicity ${ }^{24}$ and increased half-life of the drug. ${ }^{24-26}$ All of these features were achieved through the improved of drugs delivery by magnetic nanoparticles with its unique characteristics as drug carriers. ${ }^{21,27}$

Recently, much attention has been paid to the use of nanoparticles as carriers for drug delivery. ${ }^{14,28,29}$ Nanoparticle carriers can improve drug performance and reduce side effects. $^{30,31}$ In the manufacture of the nanoparticles, various materials to transfer drugs such as polymers, ${ }^{10,32-35}$ metals, lipids, layered double hydroxides, magnetic NPs decorated lipophilic dyes (magnetoliposomes), chitosan nanoparticles, gold and silver nanoparticles, ${ }^{2,36-45}$ etc. were used as drug carriers with different shapes and sizes, as well as the fabrication methods. ${ }^{46-49}$

Magnetic nanoparticles as core are of great importance in DDS due to their inherent magnetism and ability to selectively attached to the molecules or tissue specific and allow transportation to a targeted location under an external magnetic field. ${ }^{48,49}$ In addition, magnetic nanoparticles have been widely used owing to their superior properties such as targeted drug delivery and low side effects. ${ }^{50}$ Size and surface properties of magnetic nanoparticles play a significant role in determining their ability to cross the cancer cell membrane. ${ }^{51}$ Additionally, a sufficient magnetic gradient field is required to direct the nanoparticle to the target. ${ }^{52}$ For magnetic targeting, the therapeutic agent is embedded into the magnetic nanoparticles, introduced into the body and directed to the target area under magnetic field. Magnetic nanoparticles release the drug through simple penetration or through mechanisms that require enzymatic activity or temperature or $\mathrm{pH}$ changes. One of the reasons for the use of magnetic nanoparticles is their biocompatibility and toxicity. Previous studies have shown that these nanoparticles exhibit low toxicity because of the concentration required for drug delivery purposes is often lower than the levels that causing poisoning. ${ }^{53-57}$

In this study, we develop superparamagnetic core-shell nanoparticles based on $\mathrm{Fe}_{3} \mathrm{O}_{4}$ core, coated not only with polymer but also co-coating with $\mathrm{LDHs}$. $\mathrm{Fe}_{3} \mathrm{O}_{4}$ as the core is coated with PEG-Mg/Al-LDH or PEG-Zn/Al-LDH, as the shells followed by loading with 5- fluorouracil as an anti-cancer drug for the liver.

\section{Materials and methods Materials}

Deionized water $\left(18.2 \mathrm{M} \Omega \mathrm{cm}^{-1}\right)$ was used in all the experiments. Ferrous chloride tetrahydrate $\left(\mathrm{FeCl}_{2} \cdot 4 \mathrm{H}_{2} \mathrm{O}\right)$ and ferric chloride hexahydrate $\left(\mathrm{FeCl}_{3} \cdot 6 \mathrm{H}_{2} \mathrm{O}\right)$ with $99 \%$ purity were procured from Merck (Germany). Polyethylene glycol, with 6000 molecular mass was purchased from Acros Organics (USA). Ammonia solution (25\%) was acquired from Scharlau (Barcelona, Spain). Aluminum nitrate $\left(\mathrm{Al}\left(\mathrm{NO}_{3}\right)_{3} \cdot 9 \mathrm{H}_{2} \mathrm{O} \geq 98.5 \%\right)$, zinc nitrate hexahydrate $\mathrm{Zn}\left(\mathrm{NO}_{3}\right)_{2} \cdot 6 \mathrm{H}_{2} \mathrm{O}$ with $98 \%$ purity and magnesium nitrate $\left(\mathrm{Mg}\left(\mathrm{NO}_{3}\right)_{2} \cdot 6 \mathrm{H}_{2} \mathrm{O} \geq 99 \%\right)$ were supplied by ChemAR (Kielce, Poland). 5-fluorouracil $\left(\mathrm{C}_{4} \mathrm{H}_{3} \mathrm{FN}_{2} \mathrm{O}_{2}\right)$ is a liver anti-cancer drug with $98 \%$ purity was obtained from AKSci (CA, USA) and dimethyl sulfoxide $\left(\left(\mathrm{CH}_{3}\right)_{2} \mathrm{SO}\right.$ with $99 \%$ purity) was obtained from Sigma Aldrich (Germany) and they were used in this study.

\section{Methods}

To prepare $\mathrm{Fe}_{3} \mathrm{O}_{4}$ nanoparticles, a mixture of $2.4 \mathrm{~g}$ ferrous chloride tetrahydrate $\left(\mathrm{FeCl}_{2} \cdot 4 \mathrm{H}_{2} \mathrm{O}\right), 0.9 \mathrm{~g}$ ferric chloride hexahydrate $\left(\mathrm{FeCl}_{3} \cdot 6 \mathrm{H}_{2} \mathrm{O}\right)$ and $100 \mathrm{~mL}$ deionized water in the presence of $10 \mathrm{~mL}$ ammonium hydroxide $(25 \%$ by mass) It was exposed to ultrasonic irradiation for $2 \mathrm{hrs}$. Afterward, the precipitates were washed 3 times, centrifuged and dispersed in $50 \mathrm{~mL}$ mixture of $2 \mathrm{~g}$ of polyethylene glycol (PEG) in deionized water. Thereafter, the synthesized nanoparticles were left in an autoclave at $150{ }^{\circ} \mathrm{C}$ for $20 \mathrm{hr}$. To eliminate the additional PEG which does not contribute to the coating process, the black precipitates were collected and washed. The coated iron oxide nanoparticles (FPEG) was added into $3 \mathrm{~g}$ of 5-fluorouracil, which was solvable in DMSO (dimethyl sulfoxide), and 
the mixture was stirred for $24 \mathrm{hr}$. The final nanoparticles were re-dispersed in $50 \mathrm{~mL}$ deionized water and layered double hydroxide solution $(\mathrm{Mg} / \mathrm{Al})$ was added dropwise into the combination solution under strong stirring till the $\mathrm{pH}$ was decreased to 9-10.

The Mg/Al-layered double hydroxides (MLDH) nanocarrier was prepared by co-precipitation procedure. Briefly, the solution of magnesium and aluminum nitrates, $\mathrm{Mg}\left(\mathrm{NO}_{3}\right)_{2} \cdot 6 \mathrm{H}_{2} \mathrm{O}$ and $\mathrm{Al}\left(\mathrm{NO}_{3}\right)_{3} \cdot 9 \mathrm{H}_{2} \mathrm{O}$ were dissolved in $50 \mathrm{~mL}$ distilled water. At the same time, $75 \mathrm{~mL} \mathrm{NaOH}$ $(0.2 \mathrm{~mol} / \mathrm{L})$ was added dropwise with good stirring. Finally, the resulting core-shell nanoparticles were centrifuged at $5000 \mathrm{rpm}$, washed and dried in an oven at $40{ }^{\circ} \mathrm{C}$. A similar process was done to synthesise magnetic nanoparticles with $\mathrm{Zn} / \mathrm{Al}$-layered double hydroxide (ZLDH).

\section{Characterization}

In order to determine the crystal structure of the prepared samples, X-ray diffraction (a Shimadzu XRD 6000, Japan) was used in a range of $2-80^{\circ}$ using the $\mathrm{CuK}_{\alpha}$ radiation $(\lambda=1.5406 \AA)$ at $40 \mathrm{kV}$ and $30 \mathrm{~mA}$. The morphology, mean particle size and particle size distribution were examined by a transmission electron microscope (TEM, Hitachi H-7100, Tokyo, Japan) at an accelerating voltage of $100 \mathrm{kV}$ and the particle size distribution was obtained by an image analysis software (UTHSCSA Image Tool V.6). The thermal decomposition of the core-shell nanoparticles with $\mathrm{Mg} / \mathrm{Al}$ - and $\mathrm{Zn} / \mathrm{Al}-\mathrm{LDH}$ were determined by the thermogravimetric analysis (TGA/DTG) using a Mettler-Toledo instrument (Greifensee, Switzerland) from $20-1000{ }^{\circ} \mathrm{C}$ at a heating rate of $10^{\circ} \mathrm{C} \mathrm{min}^{-1}$.

To investigate the particle size distribution of the samples, dynamic light scattering (a DLS, MALVERN, Nano $\mathrm{S}, \mathrm{UK})$ was used. The samples were diffused in methanol and exposed to ultrasonic irradiation for $1 \mathrm{~h}(40 \%$ power in $40{ }^{\circ} \mathrm{C}$ ) prior to the measurement of the drug loading. Percentage of the drug loading of the samples was determined using the high-performance liquid chromatography (an HPLC, ALLIANCE, e2695, USA). Fourier transform infrared (FTIR) spectra were recorded in the range between $400-4000 \mathrm{~cm}^{-1}$ on a Thermo Nicolet 6700 (AEM, Madison WI, USA) with $0.09 \mathrm{~cm}^{-1}$ resolution, using the potassium bromide disk method.

To study the magnetic properties, a vibrating sample magnetometer (VSM, Lakeshore 7404, Westerville, OH, USA) was used. A field emission scanning electron microscope (FESEM, NOVA NANOSEM 230, California,
USA) was used to investigate the shape and morphology of the nanoparticles. A CHNSO (LECO, TruSpec, Stockport, UK) analyzer was used to determine the percentages of oxygen, nitrogen, hydrogen, sulphur and carbon compounds. The magnesium, zinc, aluminum and iron content of the nanoparticles was studied with a PerkinElmer spectrophotometer (Perkin Elmer, Wellesley, MA, USA) (Model Optima 8300) inductively coupled plasma atomic emission spectrometry (ICP-ES).

For TEM, VSM, SEM, XRD and TGA analyses, the samples were first dried in an oven at $40^{\circ} \mathrm{C}$ for $24 \mathrm{hrs}$. To determine the particle size distribution, the sample in water was ultrasonicated using an ultrasonic bath. For the high-performance liquid chromatography and CHNSO analyses, first, the samples were diluted in methanol and PBS at $\mathrm{pH} 7.4$ with the ratio of $1: 1$ and ultrasonicated before the measurement. For the FTIR study, the $\mathrm{KBr}$ technique was adopted and the FTIR spectra were obtained in the range of $4000-500 \mathrm{~cm}^{-1}$. Purification of the nanoparticles from excess polymer and drug before further characterization of the composition and loading was done by washing the sample 3 times with excess deionized water. We found that such a step was good enough to give a consistence result.

\section{Cell culture and MTT cell viability assays}

Cell viability assay was conducted to analyze the toxicity level of the nanoparticle to cell lines. Two types of cells were used for the cytotoxicity assay; the healthy human fibroblast (3T3) and human hepatocellular carcinoma cells (HepG2) which were purchased from ATCC (Manassas, USA). Both cells were grown in the Roswell Park Memorial Institute (RPMI) of 1640 medium (Nacalai Tesque, Kyoto, Japan) supplemented with $10 \%$ fetal bovine albumin (Sigma-Aldrich, MO, USA), 1\% antibiotics containing 10,000 units/mL penicillin and 10,000 $\mu \mathrm{g} /$ $\mathrm{mL}$ streptomycin (Nacalai Tesque, Kyoto, Japan). Cells were maintained and incubated in humidified 5\% carbon dioxide $/ 95 \%$ room air at $37{ }^{\circ} \mathrm{C}$. Cells layers were harvested using $0.25 \%$ trypsin/1mM-EDTA (Nacalai Tesque, Kyoto, Japan). This followed by seeded in a 96-well tissue culture plates at $1.0 \times 10^{4}$ cells/well for $24 \mathrm{hrs}$ in an incubator to attach and $90 \%$ confluence attained for treatment.

Methylthiazol tetrazolium (MTT)-based assay was carried out to determine the cell viability and cytotoxicity. Cells were treated with iron oxide (Fe), FPEG, FPEGMLDH, FPEG-ZLDH (the nanocarriers), 5-fluorouracil (drug pure compound), FPEG-FU-MLDH and FPEG-FU- 
ZLDH (nanoparticles), where stock solutions were prepared by dissolving the compound in 1:1 of dimethyl sulfoxide $(0.1 \%)$ and RPMI. Then, the mixture was further diluted in the same media to produce various final concentrations, ranging from 1.25 to $100 \mu \mathrm{g} / \mathrm{mL}$. Once the cells were attached to the respective wells after $24 \mathrm{hrs}$, the tested compounds were added until the final volume of $100 \mu \mathrm{L}$ well was obtained. After $72 \mathrm{hrs}$ of incubation, $10 \mu \mathrm{L}$ of MTT solution ( $5 \mathrm{mg} / \mathrm{mL}$ in PBS) was added in each well and further incubated for $3 \mathrm{hrs}$ before being aspirated. Then $100 \mu \mathrm{L}$ of dimethyl sulfoxide was added per well in the dark and room temperature in order to dissolve the purple formazan salt. The intensity of the purple formazan solution, which reflects cell growth was subsequently measured at a wavelength of $570 \mathrm{~nm}$ using a microplate reader (Biotek LE800, Winooski, Vermont, USA).

\section{Results and discussion}

\section{X-ray diffraction}

The diffraction planes of (003) and (006) at $10.9^{\circ}$ and $22.1^{\circ}$, respectively were observed, indicating the characteristic peaks of pure $\mathrm{Zn} / \mathrm{Al}-\mathrm{LDH}, 2 \mathrm{D}$-layered structure
(Figure 1E). In addition, the XRD pattern for MLDH with high intensity of (003), (006) and (009) reflections were observed at the $2 \theta$ positions of $11.5^{\circ}$ and $23.2^{\circ}$ and $34.8^{\circ}$, respectively (Figure 1D). Additionally, 6 characteristic peaks of iron oxide with a cubic inverted spinel structure were also observed at $2 \theta=30.16^{\circ}, 35.95^{\circ}$, $43.34^{\circ}, 54.17^{\circ}, 57.27^{\circ}$ and $62.98^{\circ}$ (JCPDS No: 82-1533) (Figure 1C). ${ }^{30}$ Pure PEG is represented by two main diffraction peaks of high intensity at $19.3^{\circ}$ and $23.50^{\circ}$ (Figure 1F). ${ }^{34,58}$ The characteristic peak of 5-FU appeared at $28.44^{\circ}$ (Figure $\left.1 \mathrm{G}\right) .^{59}$ The XRD peaks of core-shell nanoparticles with MLDH and ZLDH nanocarriers are presented in Figure $1 \mathrm{~A}$ and $\mathrm{B}$, respectively.

Based on Figure 1, the XRD pattern is dominated by $\mathrm{Fe}_{3} \mathrm{O}_{4}$ as shown by the reflections indicated for the $\mathrm{Fe}_{3} \mathrm{O}_{4}$ phase. However, the presence of a small amount of $\mathrm{Fe}_{2} \mathrm{O}_{3}$ cannot be ruled out. It was obvious that the coating process did not significantly change the dominated phase of $\mathrm{Fe}_{3} \mathrm{O}_{4}$ nanoparticles. Furthermore, it can be seen that polyethylene glycol was coated onto the $\mathrm{Fe}_{3} \mathrm{O}_{4}$ nanoparticles. Characteristic peaks related to the drug, 5-FU was also observed on both samples, indicating that the drug, 5-

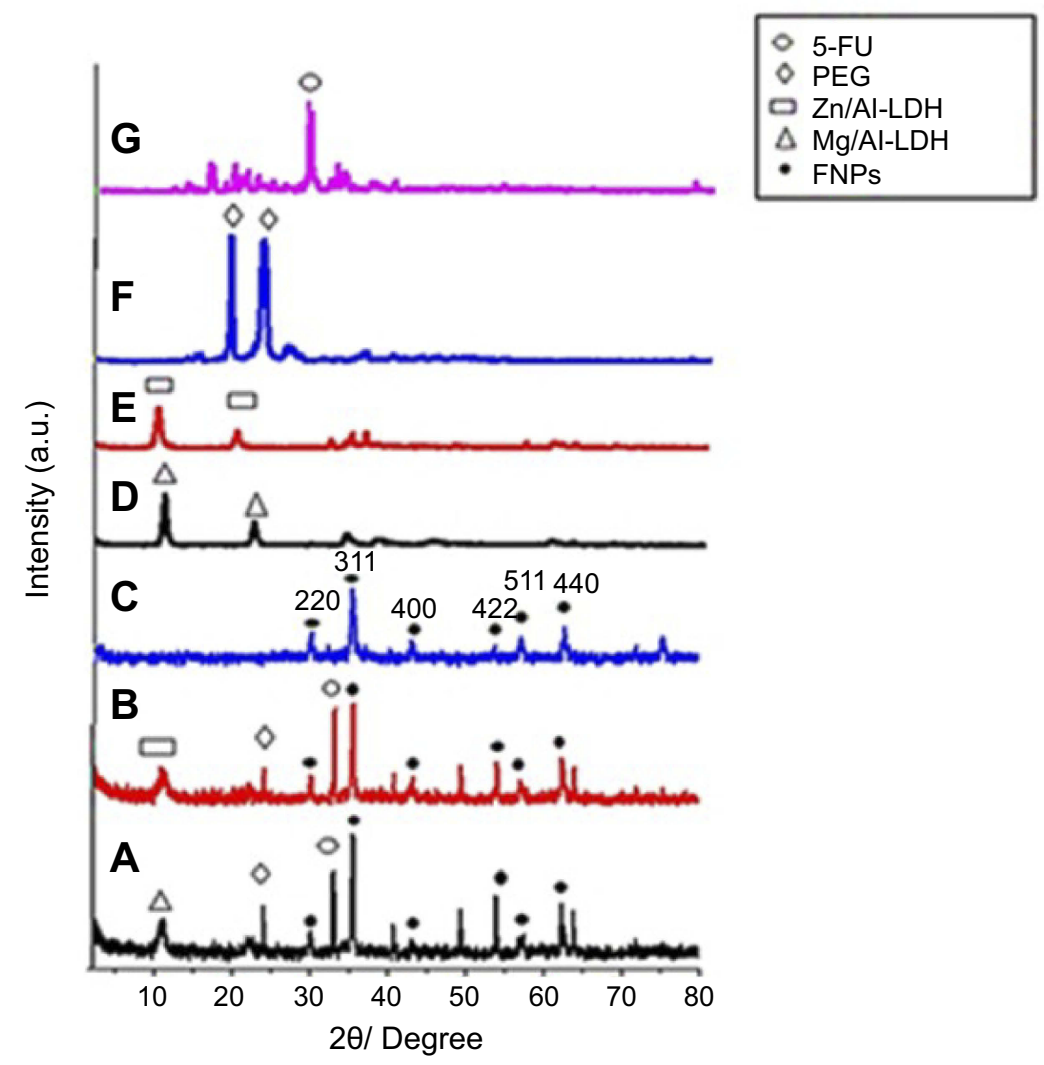

Figure I XRD patterns of (A) core-shell nanoparticles coated with Mg/Al-LDH, (B) core-shell nanoparticles coated with Zn/Al-LDH, (C) pure FNPs, (D) Mg/Al-LDH, (E) $\mathrm{Zn/AI-LDH,} \mathrm{(F)} \mathrm{PEG,} \mathrm{(G)} \mathrm{5-FU.} \mathrm{The} \mathrm{nanoparticles} \mathrm{are} \mathrm{composed} \mathrm{of} \mathrm{pure} \mathrm{FNPs,} \mathrm{PEG,} \mathrm{5-FU} \mathrm{and} \mathrm{Mg/Al-LDH} \mathrm{(for} \mathrm{A)} \mathrm{or} \mathrm{Zn/Al-LDH} \mathrm{(for} \mathrm{B).}$ 
FU was also incorporated onto the nanoparticles. Furthermore, the peaks related to MLDH and ZLDH nanocarriers were also appeared in the synthesized samples, indicating that the nanoparticles were LDH-coated. The $\mathrm{Fe}_{3} \mathrm{O}_{4}$, PEG and 5-FU peaks can be still observed after the coating process with both LDHs, but the crystallization intensity was reduced. It is noteworthy that although the reflections for core-shell nanoparticles coated with $\mathrm{Mg} / \mathrm{Al}$ $\mathrm{LDH}$ or $\mathrm{Zn} / \mathrm{Al}-\mathrm{LDH}$ that are attributed to the various substances are not exactly identical to the peaks for the pure compounds; PEG and 5-FU together with $\mathrm{Mg} / \mathrm{Al}-$ $\mathrm{LDH}$ or $\mathrm{Zn} / \mathrm{Al}-\mathrm{LDH}$, respectively, the shifts are presumably due to the slight change in the chemical interactions of the compounds in the resulting nanoparticles.

\section{Morphology and particle size distribution}

The size and particle size distribution of magnetic nanoparticles play a significance role in the drug delivery system. Furthermore, for magnetic nanoparticles, their physical and chemical properties in aqueous environments like blood depend on their size. Therefore they often shipped as dry powders and dispersed in an aqueous environment for later use, and the later causes most of the particles to be agglomerated. Therefore their stability has to be evaluated by FESEM and DLS analyses.

As will be mentioned later, iron oxide particles are usually strongly agglomerated. In fact, when the particle size is reduced, their ratio of the surface to volume is increased and as a result, the weight of the particles also increased which leads to the formation of agglomerates. These agglomerates result from the aggregation of the small size of the synthesized particles. In this work, after the samples were prepared, their stability of the nanoparticles was compared. The results showed that sample b, which had been co-coated with $\mathrm{Mg} / \mathrm{Al}-\mathrm{LDH}$, was found to be more stable than sample c.
A

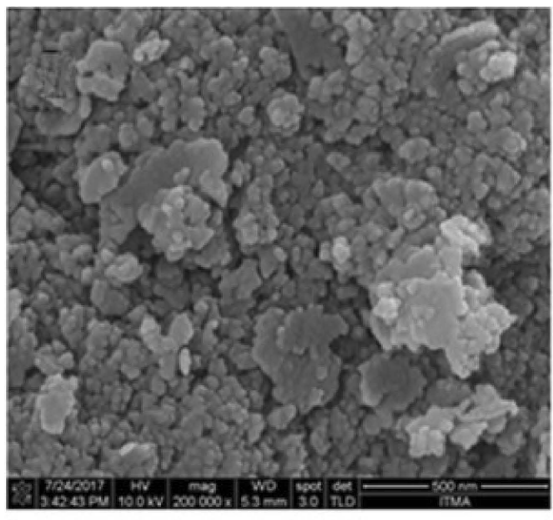

B

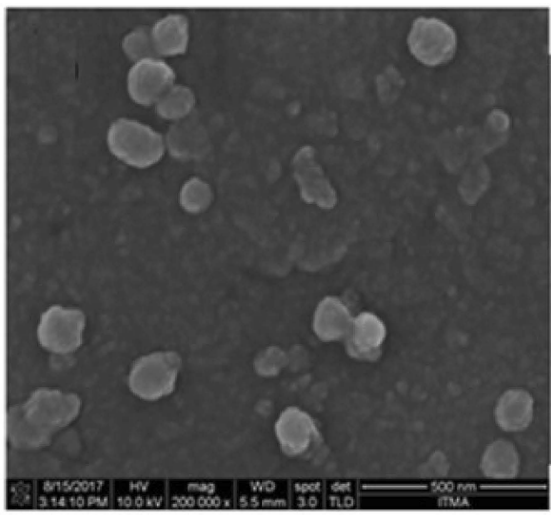

C

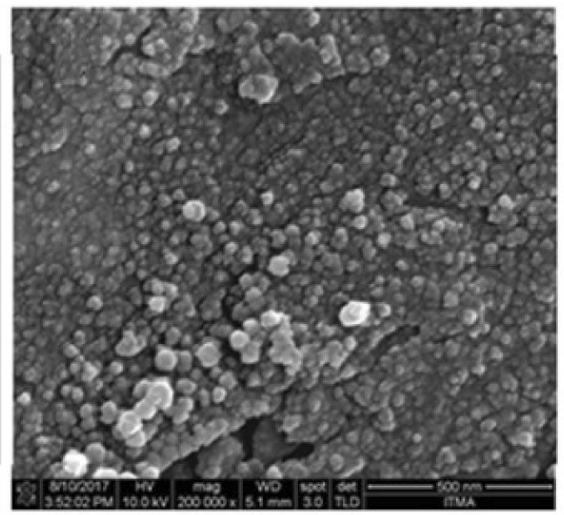

D

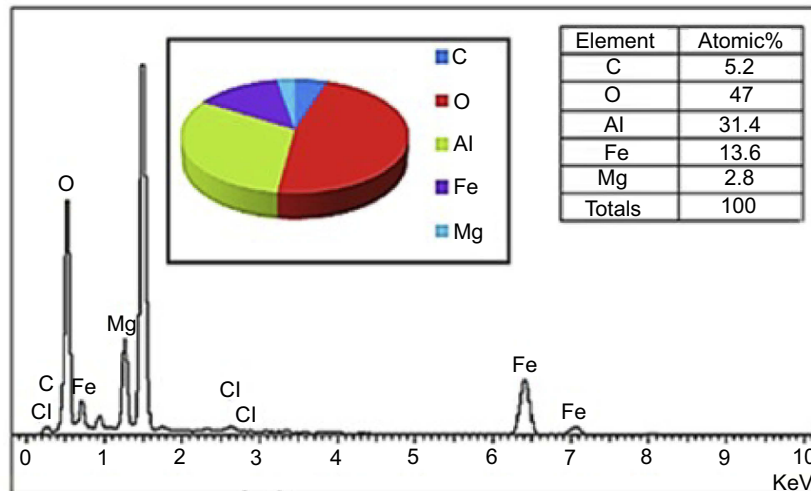

E

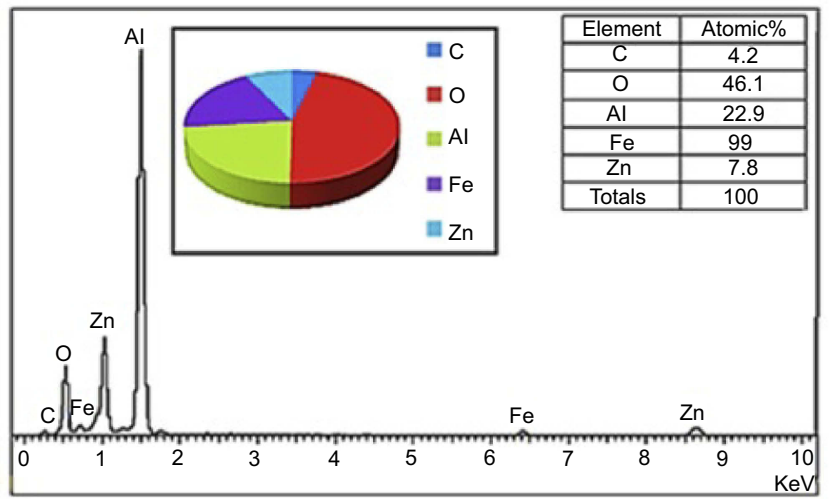

Figure 2 Field emission scanning electron micrograph (FESEM) of (A) FNPs, (B) the nanoparticles co-coated with Mg/AI-LDH, (C) the nanoparticles co-coated with Zn/Al$\mathrm{LDH}$ and EDX spectra of (D) the nanoparticles co-coated with Mg/AI-LDH, (E) the nanoparticles co-coated with $\mathrm{Zn} / \mathrm{Al}$-LDH. *The sample holder is made of aluminum, therefore resulting in a high percentage of aluminum, and therefore it is not reliable to indicate the aluminum content of the sample. 
Figure 2 shows the field emission scanning electron micrographs (FESEM) of the iron oxide nanoparticles (Figure 2A), the nanoparticles co-coated with MLDH (Figure 2B) and the nanoparticles co-coated with ZLDH (Figure 2C) at magnifications of 200,000x. These images show that the nanoparticles of both samples are agglomerated, presumably during the time of the drying process. The degree of agglomeration was reduced as observed after the iron oxide nanoparticle was coated with PEG polymer, the LDHs and the drug. The FESEM images show that the surface of the particles is slightly spherical. However, the particle sizes of these nanoparticles, determined from SEM images and DLS are slightly larger than those reported by the TEM.

The compositional analyses of the nanoparticles with obtained from SEM-EDX study confirms the presence of all the compositional elements in the nanoparticles. The
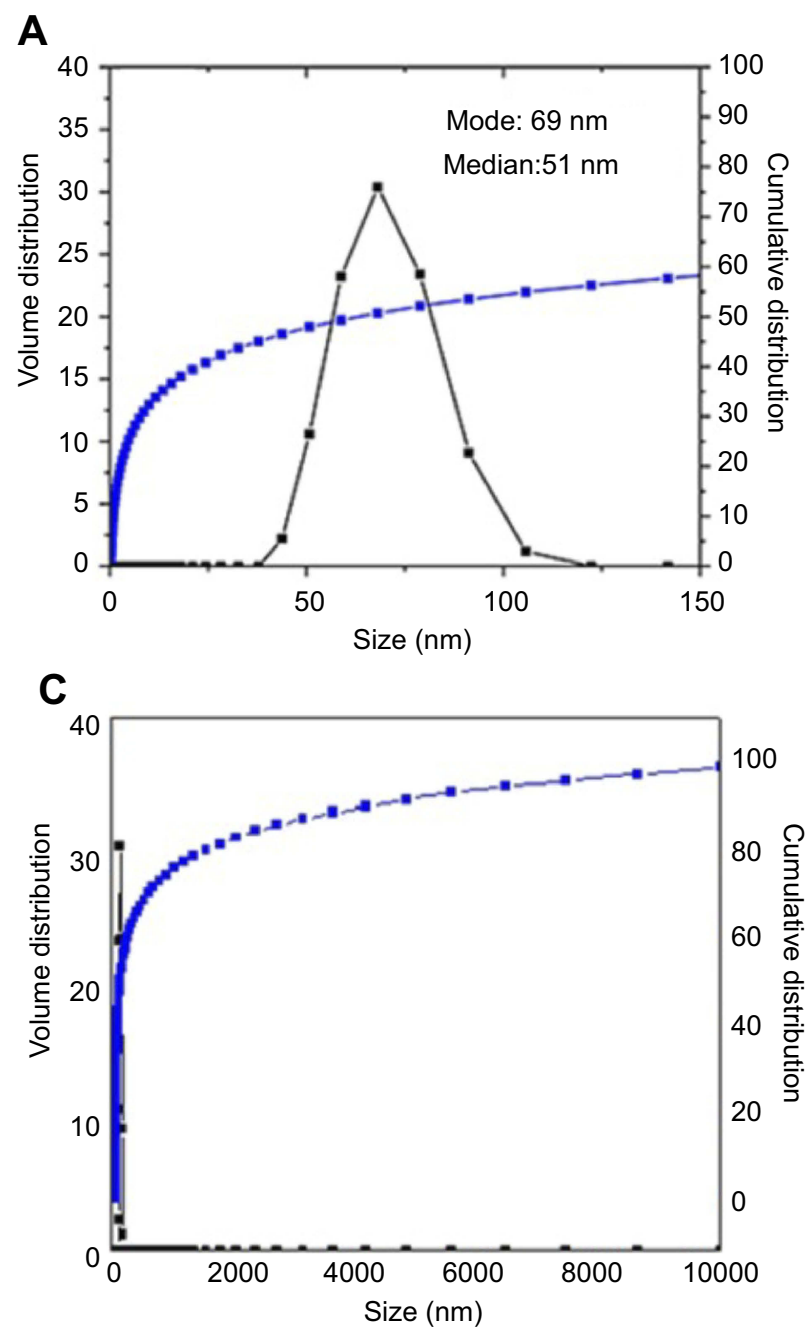

data obtained from EDX study is presented in Figure 2. The table in Figure 2D and E indicate the atomic percentage of iron and oxygen in the synthesized nanoparticles, which is $13.6 \%$ and $47 \%$, respectively for the nanoparticles co-coated with $\mathrm{Mg} / \mathrm{Al}-\mathrm{LDH}$ compared to $19 \%$ and $46.1 \%$, respectively for the nanoparticles co-coated with $\mathrm{Zn} / \mathrm{Al}-\mathrm{LDH}$. For PEG-coated FNPs and Mg/Al-LDH, the atomic percentages of carbon, magnesium and aluminum were found to be 5.2, 2.8 and $31.4 \%$, respectively as shown in Figure 2D. For PEG and Zn/Al-LDH coated nanoparticles, the atomic percentages of carbon, zinc and aluminum were found to be $4.2,7.8$ and $22.9 \%$, respectively (Figure 2E). The presence of PEG is evident from the appearance of the peak of carbon. The presence of zinc, magnesium and aluminum are resulting from the nanocarriers; MLDH and ZLDH used for the preparation process. The binding energies of iron for the whole core-

B
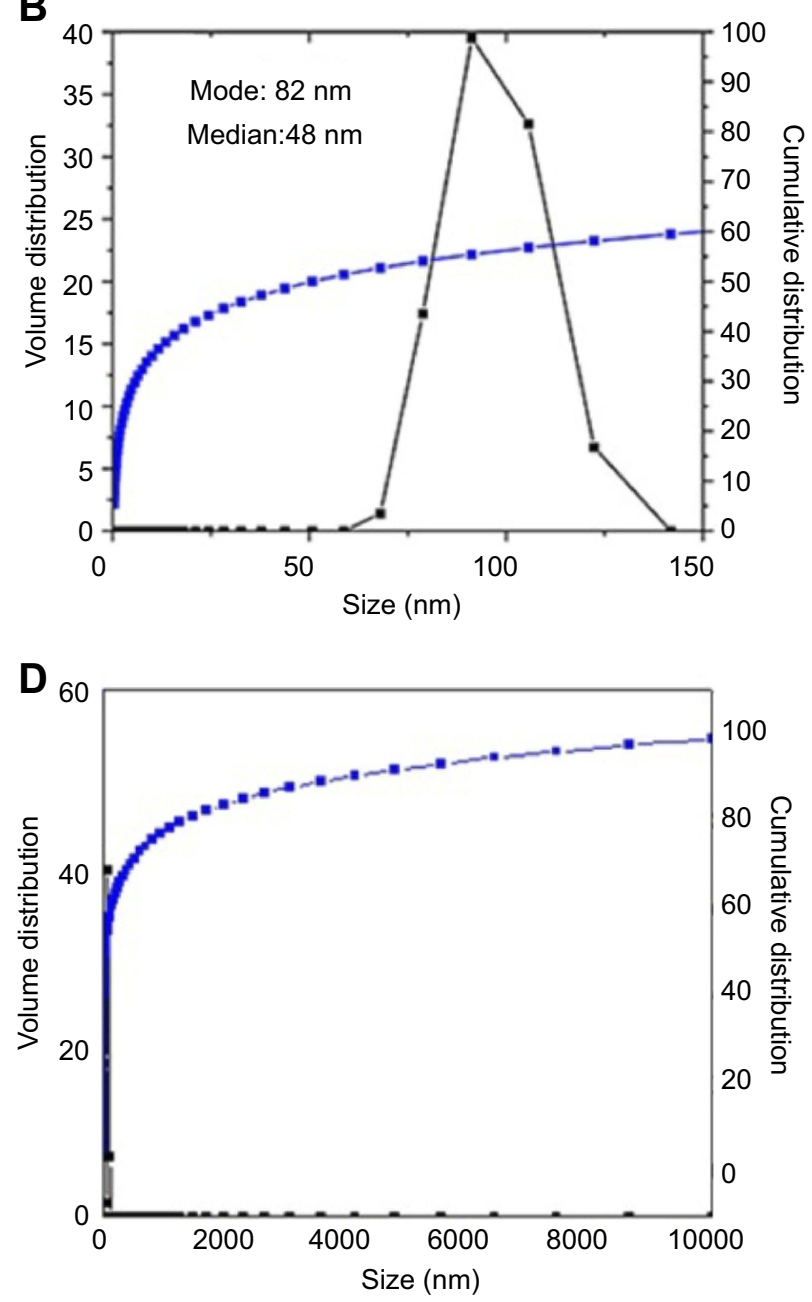

Figure 3 DLS particle size distribution of the nanoparticles co-coated with (A) Mg/Al-LDH, (B) $\mathrm{Zn} / \mathrm{Al}$-LDH and their I00\% cumulative is given in C and D, respectively. 
shell nanoparticles are presented by peaks observed at the energy values of 0.7 and $6.4 \mathrm{keV}^{37,38}$

The particle size distribution of the nanoparticles synthesized in this work was found to depend on the co-coated agents, MLDH and ZLDH, which was studied via dynamic light scattering (DLS) as revealed in Figure 3. The cumulative distribution frequency for the core-shell nanoparticles shows
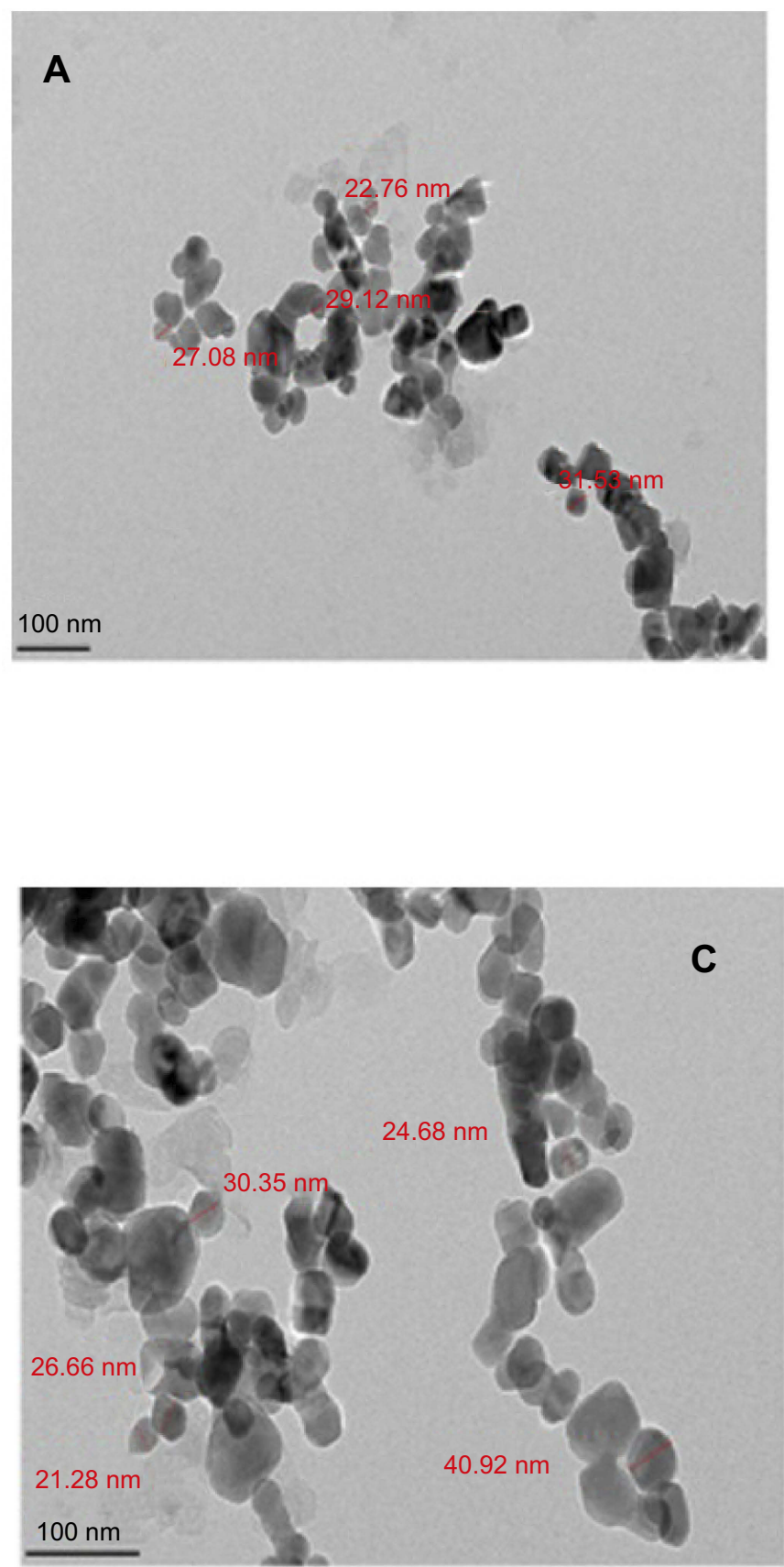
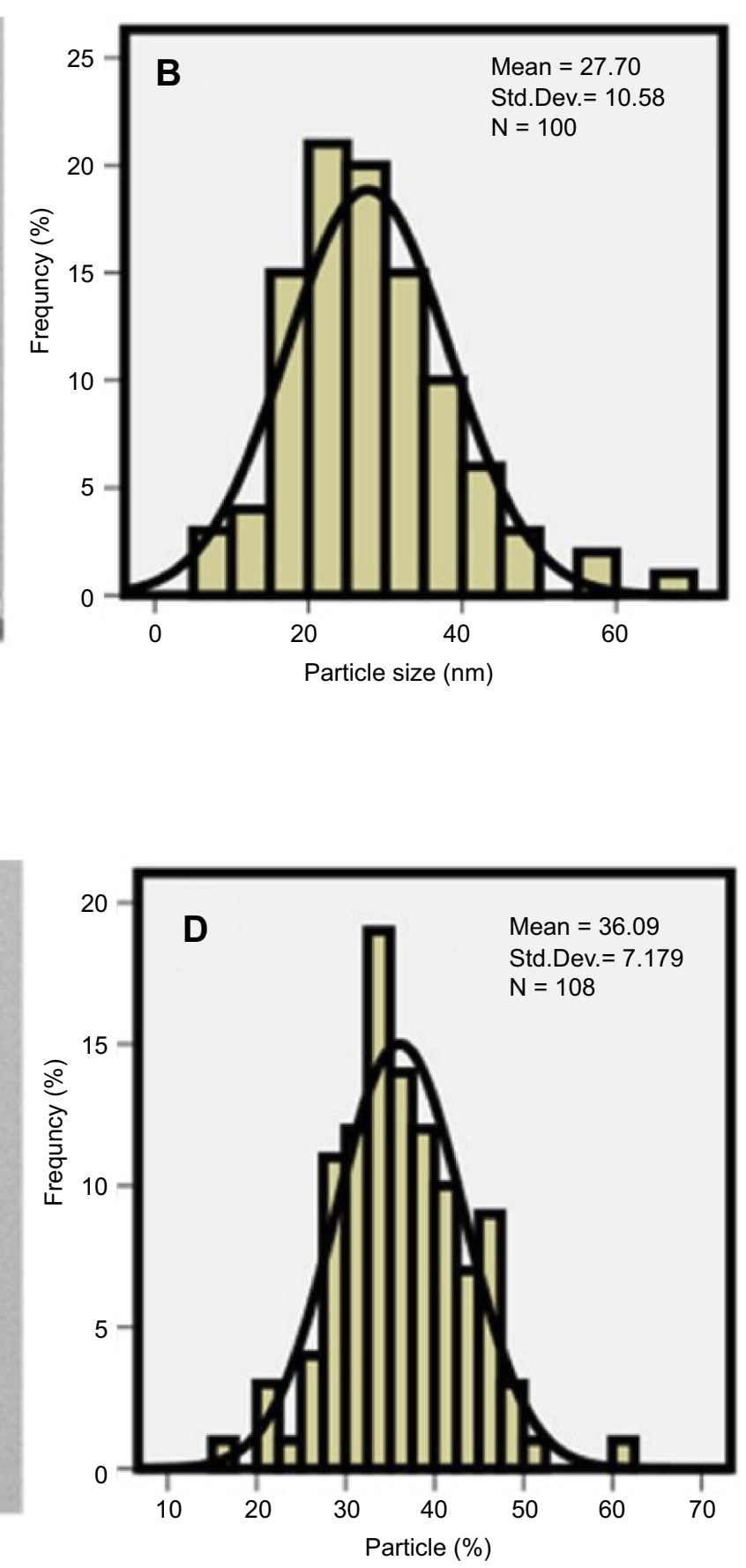

a narrow size distribution in the range of $40-110 \mathrm{~nm}$ and the hydrodynamic diameter of $69 \mathrm{~nm}$ (Figure 3A). The nanoparticles co-coated with $\mathrm{Zn} / \mathrm{Al}-\mathrm{LDH}$ revealed a narrow size distribution, between $70-125 \mathrm{~nm}$ with the hydrodynamic particle size of $82 \mathrm{~nm}$ as revealed in Figure 3B. Their 100\% cumulative distribution is given in Figure $3 \mathrm{C}$ and $\mathrm{D}$ for MLDH and ZLDH, respectively.

Figure 4 Transmission electron micrographs for (A) the nanoparticles co-coated with Mg/Al-LDH (I00 nm bar), (B) Their particle size distribution, (C) the nanoparticles co-coated with $\mathrm{Zn} / \mathrm{Al}-\mathrm{LDH}$ (100 nm bar), (D) their particle size distribution. 


\section{Mean size and particle size distribution by TEM method}

The nanoparticles size distribution is of great importance which also determines the degree of superparamagnetic properties and their retention time in the body. The size, uniformity, shape and the size distribution of the synthesized nanoparticles were studied by TEM (Figure 4A and C). The co-coated Mg/Al-LDH nanoparticles have the mean particle size of $28 \mathrm{~nm}$ with a narrow size distribution, compared to $40 \mathrm{~nm}$ for the co-coated Zn/Al-LDH nanoparticles as shown in Figure $4 \mathrm{~B}$ and $\mathrm{D})$. The size and size distribution of the nanoparticles were obtained by gauging of around 100 nanoparticles chosen randomly. It is clear that the synthesized core-shell nanoparticles were generally spherical shapes and fairly monodisperse.

It is worth noted that the core of the nanoparticles is composed of iron oxide nanoparticles (ION) coated with negatively charged drug and LDH nanocarrier. DLS gave the higher value of the particle size distribution due to the aggregation of the nanoparticles together to form larger particles as shown by FESEM study. On the other hand, HRTEM gave the actual size measurement of each of the nanoparticles in their nonagglomerated dried form. This is why the particles size distribution of the nanoparticles shows higher values when they were measured using DLS method compared to the HRTEM method.

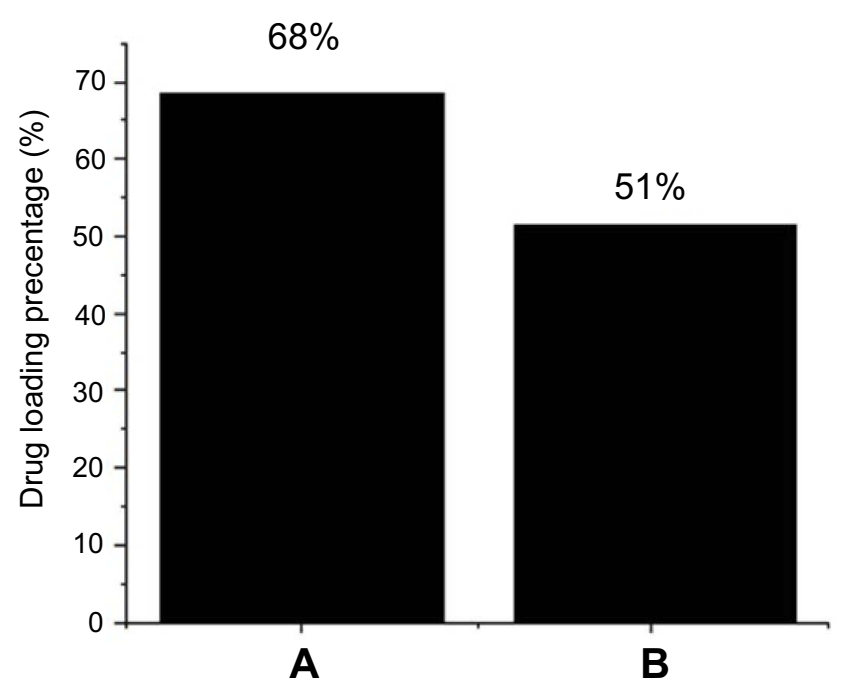

Figure 5 HPLC plot of $(\mathbf{A})$ the nanoparticles co-coated with $\mathrm{Mg} / \mathrm{Al}-\mathrm{LDH},(\mathbf{B})$ the nanoparticles co-coated with Zn/AI-LDH.

\section{Percentage loading of the drug by HPLC analysis}

High-performance liquid chromatography (HPLC) was used for the quantification of the drug loading (Figure 5). The method developed by Zhu et al. ${ }^{60}$ was used for 5-FU quantification with slight modification. ${ }^{61,62}$ In brief, a mobile phase made up of methanol and 5 mole $\mathrm{KH}_{2} \mathrm{PO}_{4}(\mathrm{pH}$ 6.0) in a ratio of $4: 96 \mathrm{v} / \mathrm{v}$ and the flow rate was set to $1 \mathrm{~mL} /$ minute. Agilent C18 column (3.9X150, $4.6 \mu \mathrm{m})$ was used with the column oven temperature of $30{ }^{\circ} \mathrm{C}$ and photodiode array detector (PDA) was used in a Waters HPLC 2695 separation module. Prior to sample analysis, standards of 5-FU; 25, 50, 100, 150 and $200 \mathrm{ppm}$ and a calibration curve was formed with $\mathrm{R}^{2}$ of 0.99. The drug, 5-FU loading percentage of the core-shell nanoparticles using MLDH and ZLDH was found to be $68 \%$ and $51 \%$, respectively. The LDHs alone have been reported to have lower drug loading in the literature and the higher loading may possibly attribute to the core-shell structure, and the presence of polymer provides many functional groups for more interaction with the drug molecules on the surface of the drug delivery systems. ${ }^{61-65}$

\section{Magnetic properties}

Superparamagnetic properties are important in magnetic targeted drug delivery system. Hysteresis loops of naked iron oxide nanoparticles (Figure $6 \mathrm{~A}$ ), $\mathrm{Fe}_{3} \mathrm{O}_{4}$ coated with $\mathrm{PEG}$ and co-coated with $\mathrm{Mg} / \mathrm{Al}-\mathrm{LDH}$ (Figure 6B) and $\mathrm{Fe}_{3} \mathrm{O}_{4}$ cocoated with $\mathrm{Zn} / \mathrm{Al}-\mathrm{LDH}$ (Figure $6 \mathrm{C}$ ) characterized by a vibrating sample magnetometer (VSM) at room temperature show they have superparamagnetic properties. The parameters in vibrating sample magnetometers (VSM) extracted from the values of saturation magnetization $\left(\mathrm{M}_{\mathrm{s}}\right)$, remnant magnetization $\left(\mathrm{M}_{\mathrm{r}}\right)$ and high coercivity $\left(\mathrm{H}_{\mathrm{c}}\right)$ are revealed in Table 1. The superparamagnetic materials show that they have high saturation magnetization and zero coercivity and remanence magnetization. ${ }^{66,67}$

The saturation magnetization of the prepared magnetic nanoparticles, $\mathrm{Fe}_{3} \mathrm{O}_{4}$ was about $58 \mathrm{emu} / \mathrm{g}$, slightly higher compared to $40 \mathrm{emu} / \mathrm{g}$ for $\mathrm{Fe}_{3} \mathrm{O}_{4}$ coated with PEG and $\mathrm{Mg} / \mathrm{Al}-\mathrm{LDH}$, and $27 \mathrm{emu} / \mathrm{g}$ for $\mathrm{Fe}_{3} \mathrm{O}_{4}$ coated with PEG and $\mathrm{Zn} / \mathrm{Al}-\mathrm{LDH}$. After $\mathrm{Fe}_{3} \mathrm{O}_{4}$ was coated with PEG and co-coated with MLDH and ZLDH, the saturation magnetization was reduced which could be attributed to the coating materials on the surface of magnetic nanoparticles. This saturation magnetization was further reduced after the addition of the drug, due to the presence of another layer on the iron oxide nanoparticles (Figure 6D and E). 


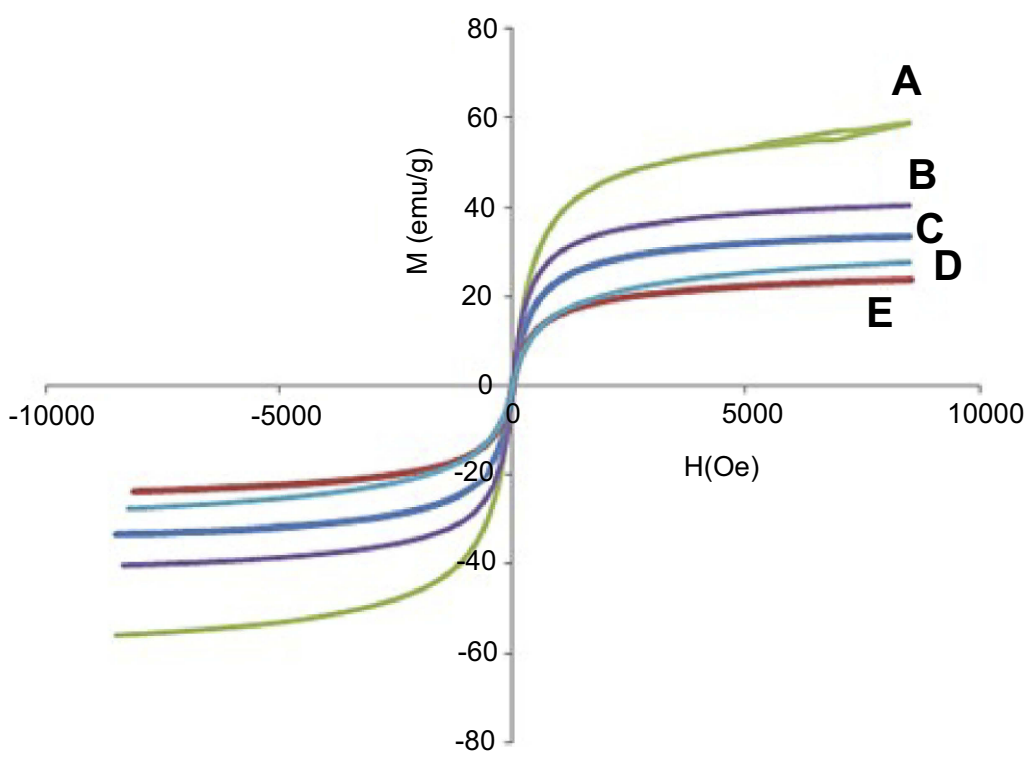

Figure 6 Magnetization curves of (A) FNPs, (B) FPEG-Mg/Al-LDH, (C) FPEG-Zn/Al-LDH, (D) the nanoparticles co-coated with Mg/Al-LDH, (E) the nanoparticles cocoated with $\mathrm{Zn} / \mathrm{Al}-\mathrm{LDH}$ recorded at room temperature.

Table I Magnetic properties of the nanoparticles

\begin{tabular}{|l|l|l|l|}
\hline samples & Ms (emu/g) & $\begin{array}{l}\text { Mr (emu/g) Magnetization } \\
\text { remanent retentivity }\end{array}$ & Hc (G) coercivity \\
\hline FNPs & 58.987 & 1.571 & 24.955 \\
FPEG-Mg/AI-LDH & 40.415 & 1.133 & 17.727 \\
FPEG-Zn/AI-LDH & 27.677 & 1.222 & 16.854 \\
core-shell-Mg/Al-LDH & 33.472 & 0.836 & 14.977 \\
core-shell-Zn/Al-LDH & 23.476 & 0.511 & 10.292 \\
\hline
\end{tabular}

Although the remanent magnetization and coercivity $\left(\mathrm{H}_{\mathrm{c}}\right)$ of pure $\mathrm{Fe}_{3} \mathrm{O}_{4}$, FPEG-MLDH and FPEG-ZLDH nanoparticles were low, all of them retain their superparamagnetic properties due to the high value of saturation magnetization. This means that they do not maintain their magnetic behavior after the removal of the external magnetic field. ${ }^{68}$ It should be noted that the synthesis method and the type of nanocarrier, as well as the stabilizer, could affect the value of saturation magnetization. ${ }^{69,70}$ Based on the results, the reduction in saturation magnetization of $\mathrm{Fe}_{3} \mathrm{O}_{4}$ after they were coated could be due to the existence of a layer that covered the iron oxide nanoparticles on the surface and electron exchange between Fe atoms and PEG polymer coated on the surface of $\mathrm{Fe}_{3} \mathrm{O}_{4}$ nanoparticles that could affect the surface magnetic anisotropy and increase surface spins disorientation. The magnetic properties of the nanoparticles in the formulation can be utilized for target the cancer cells by the application of external magnetic field and in addition, they can also confer on the hyperthermia treatment applications in addition to the chemotherapeutic effect of 5-FU. ${ }^{62,71,72}$

\section{Fourier-transform infrared spectroscopy}

Fourier-transform infrared spectroscopy (FTIR) spectra for FNPs, MLDH, PEG, ZLDH, 5-FU and FPEG, the nanoparticles co-coated with MLDH and ZLDH are shown in Figure 7. The FNPs shows an absorption band at $560 \mathrm{~cm}^{-1}$ which relates to the stretching of $\mathrm{Fe}-\mathrm{O}$ in $\mathrm{Fe}_{3} \mathrm{O}_{4}$. Band of Fe-O was shifted to $528 \mathrm{~cm}^{-1}, 513 \mathrm{~cm}^{-1}$ and $537 \mathrm{~cm}^{-1}$ for FPEG, sample (a) and (b), respectively. These results confirmed the presence of iron oxide nanoparticles in the synthesized samples which support the XRD result. The characteristic bands of naked PEG appeared at 2881 and $1465 \mathrm{~cm}^{-1}$ which can be assigned to $\mathrm{C}-\mathrm{H}$ stretching and bending vibration, respectively. In addition, two other characteristic bands are observed at 1278 and $1058 \mathrm{~cm}^{-1}$ which belongs to the $\mathrm{O}-\mathrm{H}$ and $\mathrm{C}-\mathrm{O}-\mathrm{H}$ stretching vibration, respectively. ${ }^{10,73}$ However, in FPEG nanoparticles, 

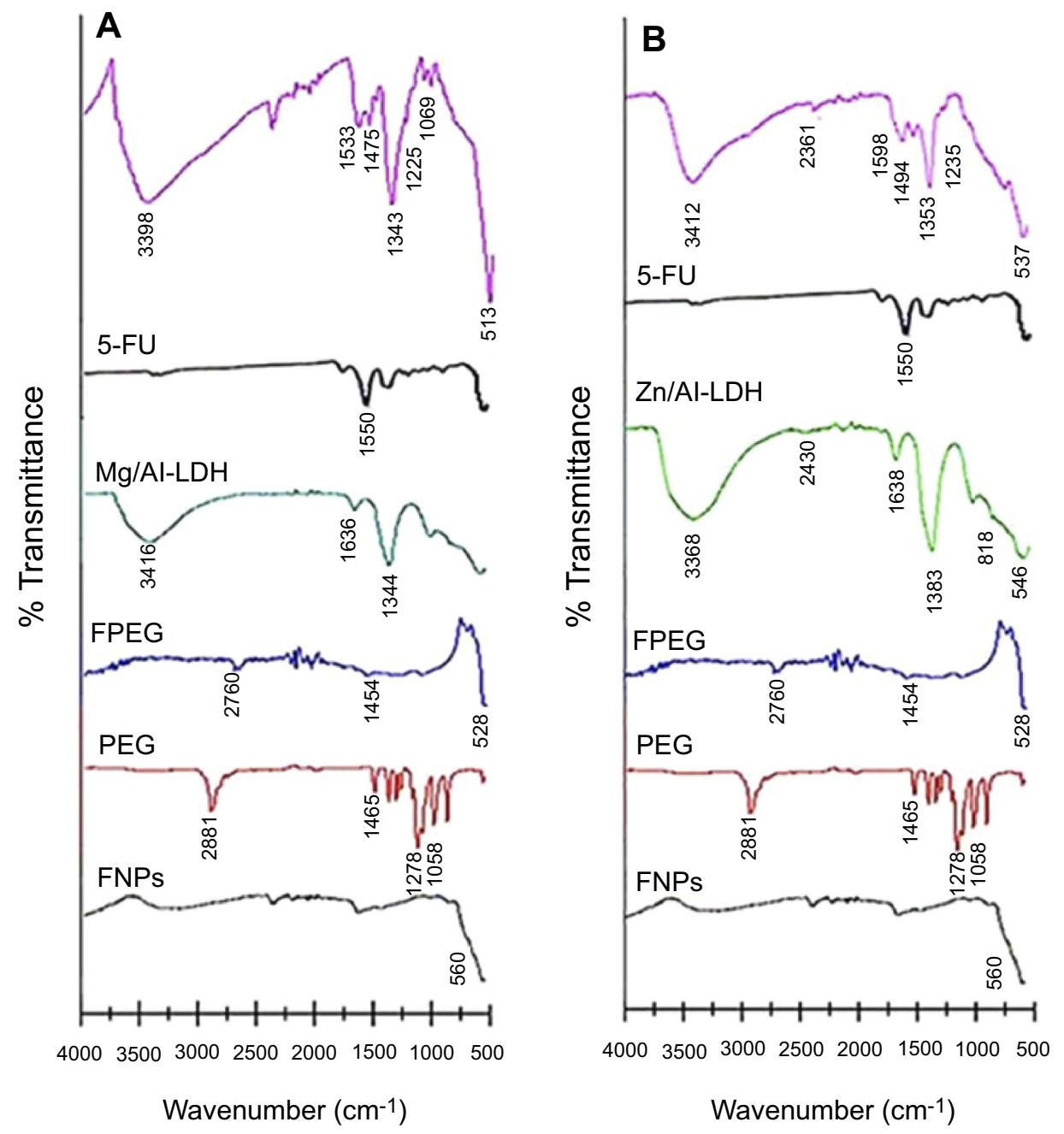

Figure 7 FTIR spectra of pure FNPs, PEG, FPEG, Mg/Al-LDH, Zn/Al-LDH and 5-FU, (A) co-coated with Mg/Al-LDH, (B) co-coated with Zn/Al-LDH.

pure PEG spectrum relates to 2881 and $1465 \mathrm{~cm}^{-1}$ were shifted to 2760 and $1454 \mathrm{~cm}^{-1}$ after the coating process. This confirms the coating of PEG on the surface of FNPs. In addition, the FTIR spectra show the characteristic bands of PEG which belong to the $\mathrm{C}-\mathrm{H}, \mathrm{O}-\mathrm{H}$ and $\mathrm{C}-\mathrm{O}-\mathrm{H}$ stretching vibrations in the nanoparticles co-coated with $\mathrm{Mg} / \mathrm{Al}-\mathrm{LDH}$ (Figure 7A) shifted to 2360, 1475, 1225 and $1069 \mathrm{~cm}^{-1}$ and in co-coated $\mathrm{Zn} / \mathrm{Al}-\mathrm{LDH}$ (Figure 7B) shifted to 2361, 1494 and $1235 \mathrm{~cm}^{-1}$, respectively. This indicates that the nanoparticles were successfully coated with PEG together with the LDHs. ${ }^{58,74}$

The FTIR spectrum of 5-FU shows the absorption bands related to primary amines groups at $1550 \mathrm{~cm}^{-1}$ and also an intense, broad band at $1281 \mathrm{~cm}^{-1}$, belongs to $\mathrm{C}-\mathrm{N}$ functional group. Absorption bands related to $\mathrm{N}-\mathrm{H}$ structure was shifted to 1533 and $1589 \mathrm{~cm}^{-1}$ in the nanoparticle of the co-coated with $\mathrm{Mg} / \mathrm{Al}-\mathrm{LDH}$ and
Zn/Al-LDH (samples a and b, respectively). The present of $-\mathrm{NH}$ and $-\mathrm{CN}$ bands is strong evidence to indicate that 5 -FU was loaded on the nanoparticles. ${ }^{75}$ The appearance of hydrogen bond related to hydroxyl layers in the nanoparticles of co-coated Mg/Al-LDH confirmed the formation of a bond between LDH and FPEG-drug nanoparticles. For example, the asymmetric and symmetric stretching mode of $\mathrm{O}-\mathrm{H}$ group in $\mathrm{Mg}$ / $\mathrm{Al}-\mathrm{OH}$ of $\mathrm{Mg} / \mathrm{Al}-\mathrm{LDH}$ at $3416 \mathrm{~cm}^{-1}$ was shifted to $3398 \mathrm{~cm}^{-1}$. ${ }^{76}$ The band at $1636 \mathrm{~cm}^{-1}$ is due to the bending vibration $(\mathrm{H}-\mathrm{O}-\mathrm{H})$ of interlayer water molecules was shifted to $1622 \mathrm{~cm}^{-1}$. In addition, the absorption band at $1344 \mathrm{~cm}^{-1}$ belongs to the stretching vibration of $\mathrm{C}-\mathrm{O}$, shifted to $1343 \mathrm{~cm}^{-1}$. The bands at $1000-500 \mathrm{~cm}^{-1}$ are due to vibrational modes of the lattice resulting from the $\mathrm{O}-\mathrm{Mg}-\mathrm{O} / \mathrm{Mg}-\mathrm{O} / \mathrm{Al}-\mathrm{O} / \mathrm{O}-$ Al-O bonds. ${ }^{77}$ 
The FTIR spectrum of ZLDH shows a broad band at $3368 \mathrm{~cm}^{-1}$, attributed to the $\mathrm{O}-\mathrm{H}$ stretching vibration of LDH layer, and the interlayer water molecules was shifted to $3412 \mathrm{~cm}^{-1}$ in sample $\mathrm{b}$. The bending vibration of $\mathrm{H}-\mathrm{O}-\mathrm{H}$ is due to the presence of water, gives rise to an absorption band close to $1638 \mathrm{~cm}^{-1}$. A band at about $1383 \mathrm{~cm}^{-1}$ is attributed to the C-O stretching vibration. However, this bond was moved to $1353 \mathrm{~cm}^{-1}$ in the nanoparticle. In
A

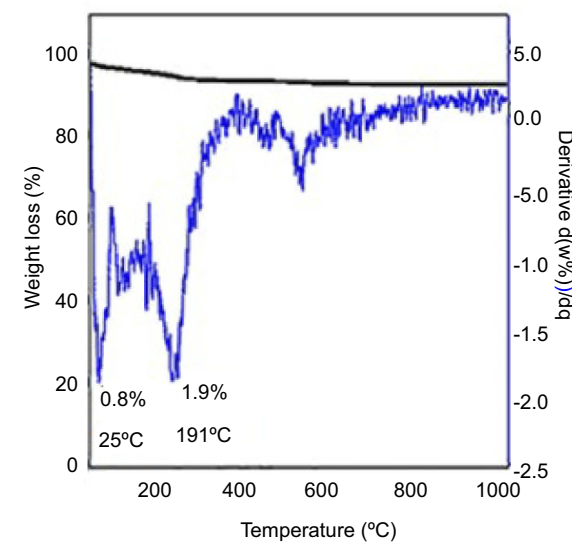

D

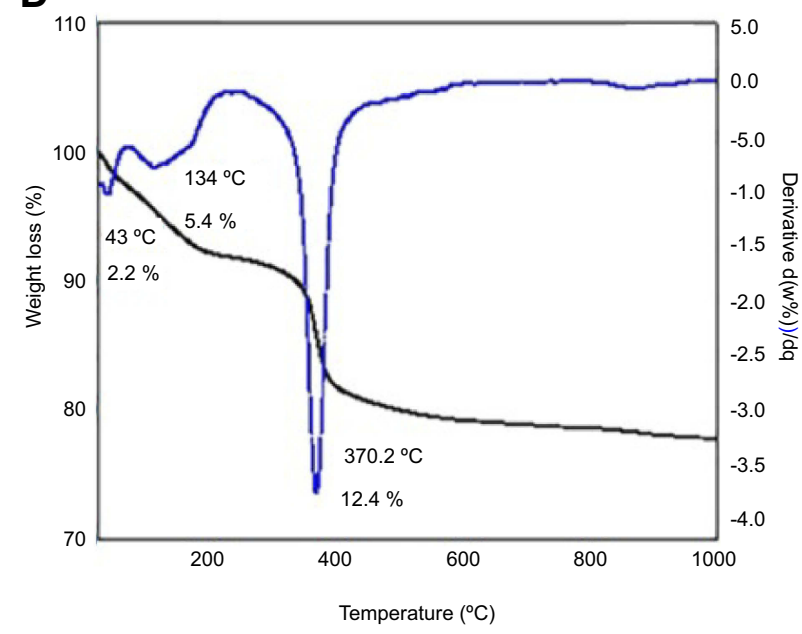

$\mathbf{F}$

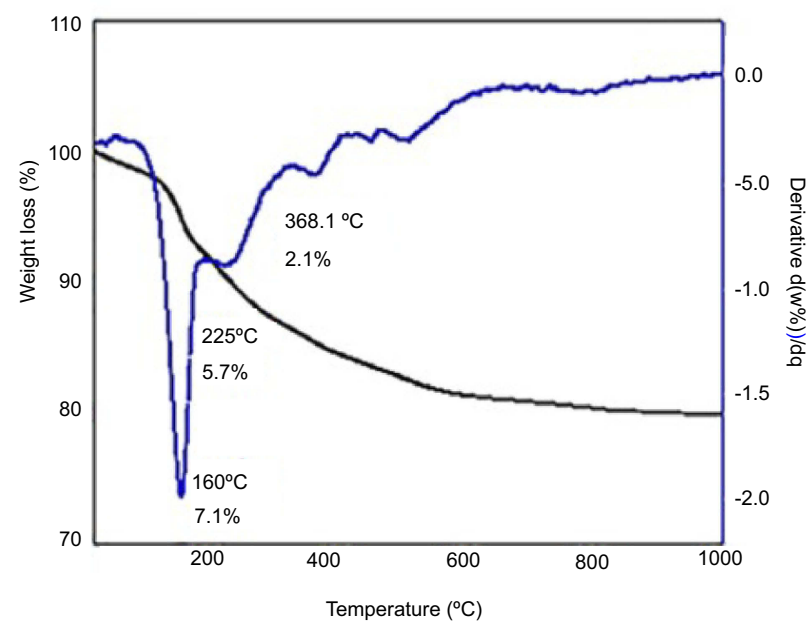

C

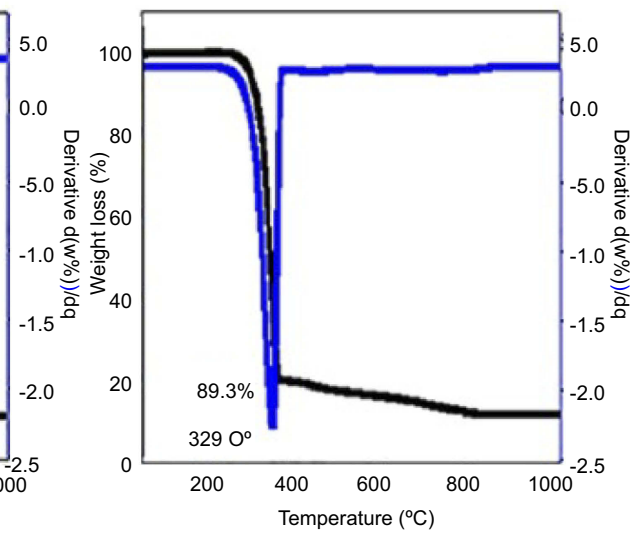

E

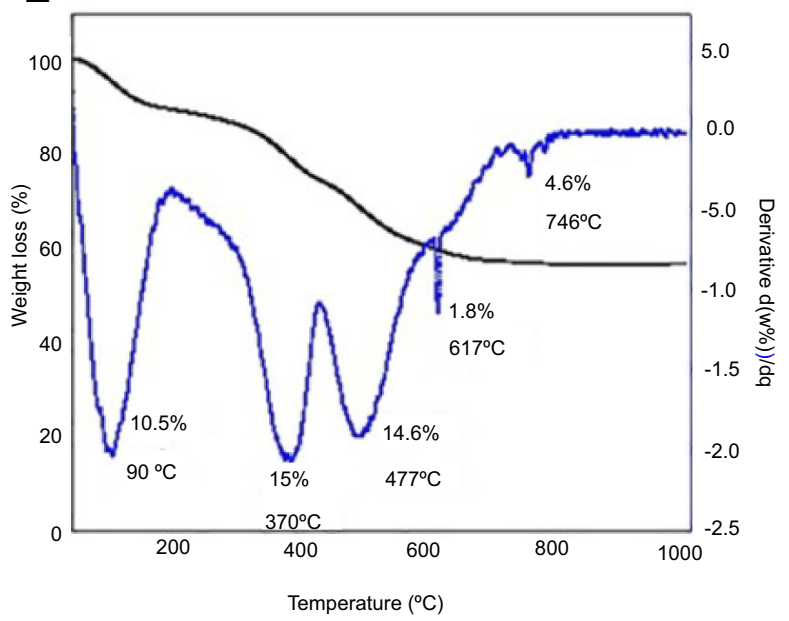

G

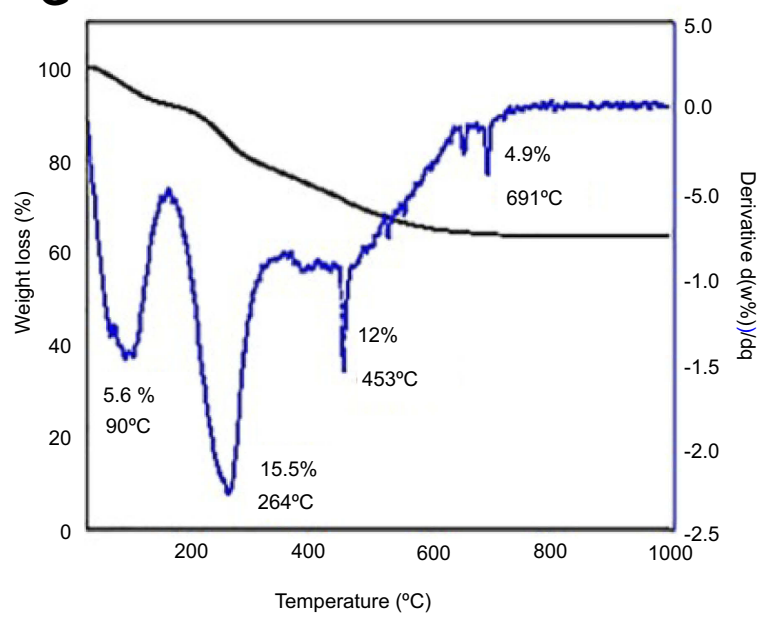

Figure 8 TGA/DTG thermograms of (A) FNPs, (B) pure PEG, (C) 5-FU, (D) Mg/Al-LDH, (E) co-coated nanoparticles with Mg/Al-LDH, (F) Zn/Al-LDH, (G) co-coated nanoparticles with $\mathrm{Zn} / \mathrm{Al}-\mathrm{LDH}$. 
addition, the bands at 818 and $546 \mathrm{~cm}^{-1}$ are due to the vibrations of $\mathrm{Al}-\mathrm{OH}$ and $\mathrm{Zn}-\mathrm{OH}$ in the layer crystal lattice, respectively. The absorption band due to $\mathrm{Zn}-\mathrm{OH}$ structure was shifted to $537 \mathrm{~cm}^{-1}$ in sample b. The presence of iron oxide and polymer in the nanoparticles co-coated with MLDH and ZLDH can be confirmed by the presence of the vibration bands at 500 and $2000-3000 \mathrm{~cm}^{-1}$, which are ascribed to the stretching vibration of $\mathrm{Fe}-\mathrm{O}$ and $\mathrm{C}-\mathrm{H}$, respectively. Furthermore, the absorption band related to the vibration of $\mathrm{N}-\mathrm{H}$ existed in the drug was found in both samples. Compared to the pure $\mathrm{Mg} / \mathrm{Al}-\mathrm{LDH}$ and $\mathrm{Zn} / \mathrm{Al}-\mathrm{LDH}$, the $\mathrm{O}-\mathrm{H}$ stretching band in the nanoparticles co-coated with MLDH and ZLDH was slightly shifted after the intercalation, presumably because of the constraint inside the interlayer space as well as the interaction with the $-\mathrm{OH}$ functional group.

\section{Thermal decomposition}

The thermogravimetric and differential thermogravimetric (TGA/DTG) behavior of FNPs, PEG, Mg/Al- and Zn/AlLDH and 5-FU are shown in Figure 8. The thermal behavior of FNPs (Figure 8A) over the temperature range between $25-1000{ }^{\circ} \mathrm{C}$ revealed that two stages of weight loss at $49{ }^{\circ} \mathrm{C}$, with weight loss of $0.8 \%$, and at $263{ }^{\circ} \mathrm{C}$ with weight loss of $1.9 \%$; both are attributed to removal of residual water in the sample. ${ }^{34}$ For PEG polymer (Figure 8B), one main thermal event was clearly observed, occurred in the region of $170-433{ }^{\circ} \mathrm{C}$ with $97.6 \%$ weight loss. $^{30}$ The TGA/DTG thermograms for 5-fluorouracil (Figure 8C) indicate a substantial mass loss of about $89.3 \%$, displaying that the 5-fluorouracil undergoes a rapid decomposition. 59

The weight loss of MLDH was occurred in three stages (Figure 8D). The first one at $43{ }^{\circ} \mathrm{C}$ with a total weight loss of $2.2 \%$ was observed. The mass reduction occurs below $100{ }^{\circ} \mathrm{C}$ can be related to the evolution of the adsorbed water or removal of free and interlayer water. ${ }^{78}$ The second sharp mass reduction step at $134{ }^{\circ} \mathrm{C}(5.4 \%)$ is due to the decomposition of dihydroxylation of the layers and the intercalated anions. The thermogravimetric curve shows one mass reduction at $370{ }^{\circ} \mathrm{C}(12.4 \%)$ and this is due to the decomposition of the interlayer of $\mathrm{NO}_{3}$ and dehydroxylation of the layers followed by the collapsed of the layered structure. The last mass reduction is due to the formation of $\mathrm{MgAl}_{2} \mathrm{O}_{4}$ spinal phase. ${ }^{19}$ Figure $8 \mathrm{E}$ displays the weight loss of the nanoparticles co-coated with $\mathrm{Mg} / \mathrm{Al}-$ $\mathrm{LDH}$ at $23-992{ }^{\circ} \mathrm{C}$ with five weight losses; $23-182{ }^{\circ} \mathrm{C}$ (10.5\%), 182-415 ${ }^{\circ} \mathrm{C}(15 \%) ; 415-597{ }^{\circ} \mathrm{C}(14.6 \%)$; 615$717{ }^{\circ} \mathrm{C}(1.8 \%)$ and $717-808{ }^{\circ} \mathrm{C}(4.6 \%)$.

$\mathrm{Zn} / \mathrm{Al}-\mathrm{LDH}$ thermogram in Figure $8 \mathrm{~F}$ shows a mass loss at $160{ }^{\circ} \mathrm{C}$ which corresponds to $7.0 \%$, owing to the removal of water molecules that has hydrogen bonding with the interlayer anion, ${ }^{79,80}$ The second decompositions

Table 2 Elemental composition of the nanoparticles

\begin{tabular}{|l|l|l|l|l|l|l|l|}
\hline Sample & C\%* & H\%* & N\%* & Zn\%** & Mg\%** & Al\%** & Fe\%** \\
\hline FNPs & 0.02 & 0.54 & 1.02 & - & - & - \\
PEG & 52.69 & 8.98 & 1.64 & - & - & 47 \\
Mg/Al-LDH & - & 3.18 & 4.64 & - & 7.3 & - & 4.5 \\
Zn/Al-LDH & - & 2.37 & 4.45 & 6.8 & - & 5.2 & - \\
5-FU & 37.76 & 2.36 & 21.5 & - & - & - \\
co-coated with MLDH & 2.32 & 2.90 & 0.16 & - & 2.1 & 3.4 & - \\
co-coated with ZLDH & 5.49 & 2.26 & 0.24 & 3.8 & - & 3.3 & 13.1 \\
\hline
\end{tabular}

Notes: *Calculated from CHNS analysis; ${ }^{* *}$ Calculated from ICP-ES analysis.

Table 3 Percentage of elements in the nanoparticles

\begin{tabular}{|c|c|c|c|c|c|c|c|}
\hline Sample & $\mathbf{C} \%$ & $\mathbf{H} \%$ & $\mathbf{N} \%$ & Zn\% & Mg\% & $\mathbf{A l} \%$ & $\mathbf{F e} \%$ \\
\hline FNPs & - & 0.54 & 0.07 & - & - & - & 8.5 \\
\hline PEG & 4.4 & 8.98 & 0.2 & - & - & - & - \\
\hline $\mathrm{Mg} / \mathrm{Al}-\mathrm{LDH}$ & - & 3.18 & 0.4 & - & 0.3 & 1.7 & - \\
\hline Zn/Al-LDH & - & 2.37 & 0.4 & 0.1 & - & 0.2 & - \\
\hline $5-\mathrm{FU}$ & 3.2 & 2.36 & 1.5 & - & - & - & \\
\hline NPs co-coated with Mg/Al-LDH & 0.2 & 2.90 & 0.02 & - & 0.1 & 0.1 & 2.3 \\
\hline NPs co-coated with Zn/AI-LDH & 0.4 & 2.26 & 0.01 & 0.06 & - & 0.1 & 3.8 \\
\hline
\end{tabular}


might be due to dehydroxylation of basic LDH layers at $228{ }^{\circ} \mathrm{C}$ with $5.7 \%$ weight loss. The third event at $368{ }^{\circ} \mathrm{C}$ results of the loss of interlayer carbonate species. ${ }^{81}$ Similarly, TGA curves of the co-coated sample with $\mathrm{Zn}$ / Al-LDH shows four decompositions (Figure $8 \mathrm{G}$ ). The one at $90{ }^{\circ} \mathrm{C}$ was about $5.6 \%$, the second and third stages were at $162-366{ }^{\circ} \mathrm{C}$ and $366-641{ }^{\circ} \mathrm{C}$, with $15.5 \%$ and $12.0 \%$ weight loss, respectively. Finally, the final residue was decomposed with a weight loss of $4.6 \%$.

Comparing the TGA thermograms of all the FNPs, PEG, 5-FU, MLDH, ZLDH with the synthesized nanoparticles, it is clear that the resulting synthesized nanoparticles are composed of polymer (PEG), drug (5-FU) and the nanocarriers (LDHs).

\section{Elemental composition by CHNS and ICP-ES analyses}

The elemental composition analysed by ICP-ES for the pure MLDH and ZLDH (Table 2) was found to be $\mathrm{Mg}$ (7.3\%), $\mathrm{Al}(4.5 \%)$ and $\mathrm{Zn}(45.0 \%), \mathrm{Al}(5.2 \%)$. The results confirmed the formation of both nanocarriers, LDHs as indicated by the XRD diffractograms and the EDX results of the samples. The ICP-ES results of the nanoparticles in Table 3 also indicate the presence of $\mathrm{Mg}, \mathrm{Zn}$ and $\mathrm{Al}$, although their percentages are low, owing to the presence of other chemicals from the other molecules. The presence of $\mathrm{Fe}$, which was used as the core, $\mathrm{C}$ and $\mathrm{O}$ also were observed in the ICP-ES and CHNS data, indicating the successful coating of iron oxide outer layer with the polymer. Additionally, the presence of $\mathrm{N}$ which specifically available in the drug structure of the 5-FU was also

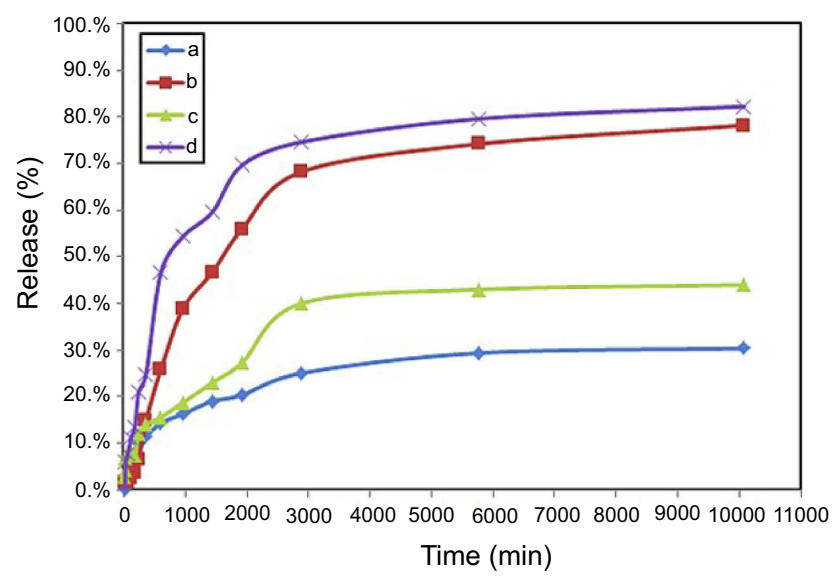

Figure 9 Cumulative release profile of 5 -fluorouracil from co-coated nanoparticles with $\mathrm{Zn} / \mathrm{Al}$-LDH in phosphate-buffer solution at $(\mathbf{A}) \mathrm{pH} 7.4$, (B) $\mathrm{pH} 4.8$ and co-coated nanoparticles with $\mathrm{Mg} / \mathrm{Al}-\mathrm{LDH}$ in phosphate-buffer solution at (C) $\mathrm{pH} 7.4$, (D) $\mathrm{pH} 4.8$. detected from the CHNS analyses, which confirm the presence of the drug in the LDH hosts.

\section{Drug release behavior}

The releases behavior of 5-fluorouracil in PBS solution is plotted in Figure 9. It can be found that both of the 5FU releases at a $\mathrm{pH}$ value of 4.8 and 7.4 displayed the trend is almost the same. After $48 \mathrm{hrs}$, the drug release plateaus were all achieved, indicating that the drug-co-coated nanoparticles with $\mathrm{Mg} / \mathrm{Al}-\mathrm{LDH}$ and $\mathrm{Zn} / \mathrm{Al}$-LDH demonstrated obviously slow and sustained release behavior. Meantime, $81 \%$ and $78 \%$ of the loaded $5 \mathrm{FU}$ from co-coated nanoparticles with Mg/Al-LDH (FPEG-FU-MLDH) and co-coated nanoparticles with Zn/Al-LDH (FPEG-FU-ZLDH) were released in the PBS solution at $\mathrm{pH} 4.8$, respectively. Meantime, $43 \%$ and $30 \%$ of the loaded 5FU from FPEGFU-MLDH and FPEG-FU-ZLDH nanoparticles were released in the $\mathrm{PBS}$ solution at $\mathrm{pH} 7.4$, respectively. The release profile in Figure 9 indicates the maximum percentages of drug release in $\mathrm{pH} 4.8$ were higher than $\mathrm{pH} 7.4$. Meaning that the 5FU-loaded FPEG-FU-MLDH and FPEG-FU-ZLDH nanoparticles had a pH-dependent characteristic for controlling release. The fast release of 5FU was mainly attributed to the higher of the 5FU-loaded in co-coated nanoparticles in an acidic environment than that in high $\mathrm{pH}$ value. Certainly, the interaction decreasing between 5-fluorouracil molecular and the carriers due to the breaking of the bonds between the polymer and the drug in the acidic PBS solution may play a role. It is worth noting that, The drug to be almost quickly released at the beginning in FPEG-FU-MLDH and FPEG-FU-ZLDH nanoparticles, in the phosphate-buffer solution with $\mathrm{pH}$ 4.8 underwent release within 32 and 48 hrs, respectively. While in $\mathrm{pH} 7.4$ the release was about in the first 10 and $16 \mathrm{hrs}$. It revealed that the drug release process has a slow, stable and excellent controlled-release property in $\mathrm{pH} 7.4$ through the ion exchange process.

\section{In vitro cell cytotoxicity assay}

All the cytotoxicity assays were carried out in triplicates and the standard deviations were calculated and are incorporated in the respective bar graphs. For the calculation of $\mathrm{IC}_{50}$, we plot the $\mathrm{x}$-against the $\mathrm{y}$-axis and converted the $\mathrm{x}$-axis values (conc.) to their log values, followed by nonlinear regression (curve fit) under the xy analysis to obtained a straight line equation fit, $y=a x+b$, from which the regression line and then inhibition $\mathrm{IC}_{50}$ was calculated. 


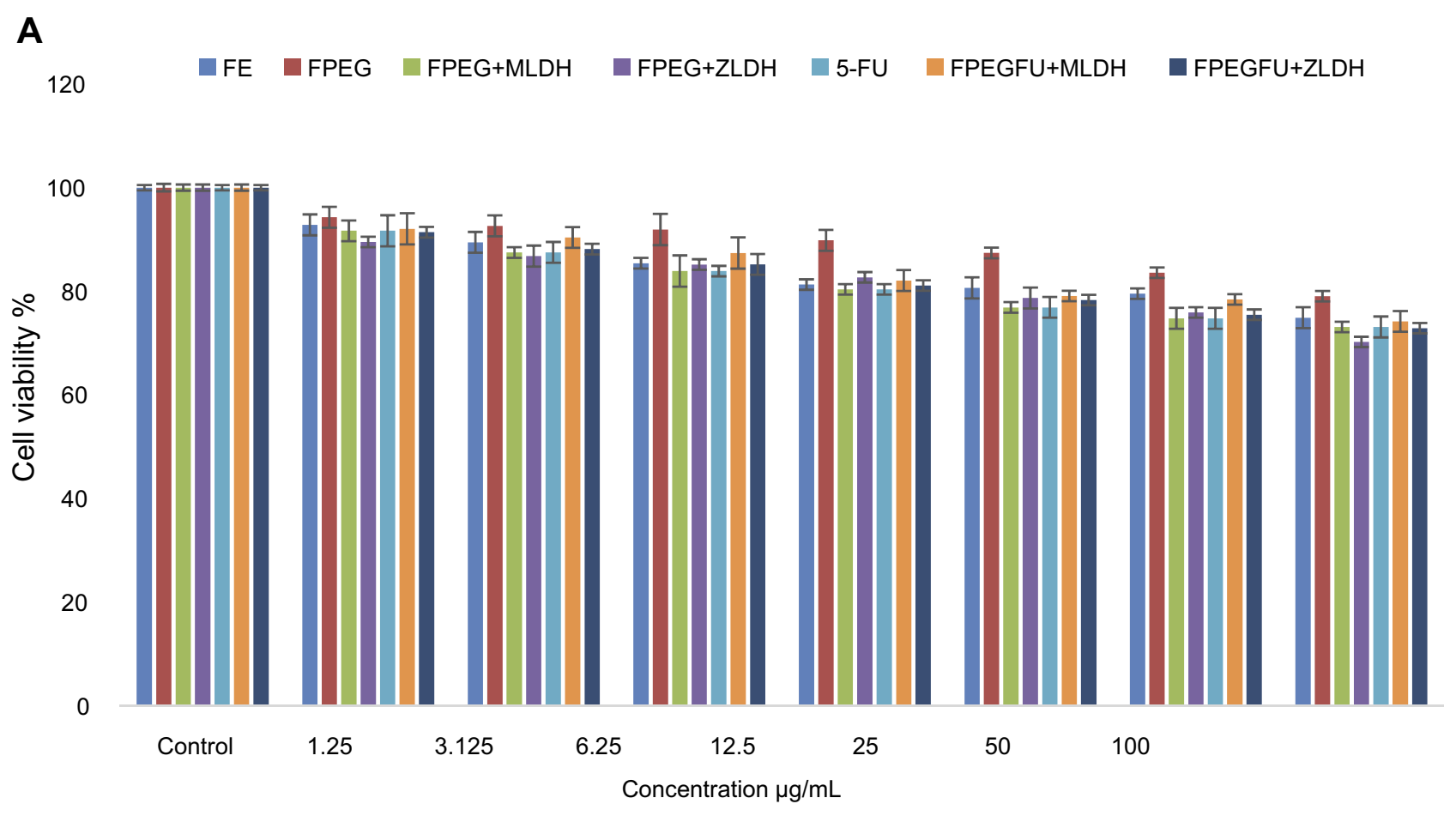

B

$120 \square \mathrm{FE} \square \mathrm{FPEG} \square \mathrm{FPEG}+\mathrm{MLDH} \square \mathrm{FPEG}+\mathrm{ZLDH} \square 5-\mathrm{FU} \square \mathrm{FPEGFU}+\mathrm{MLDH} \square \mathrm{FPEGFU+ZLDH}$

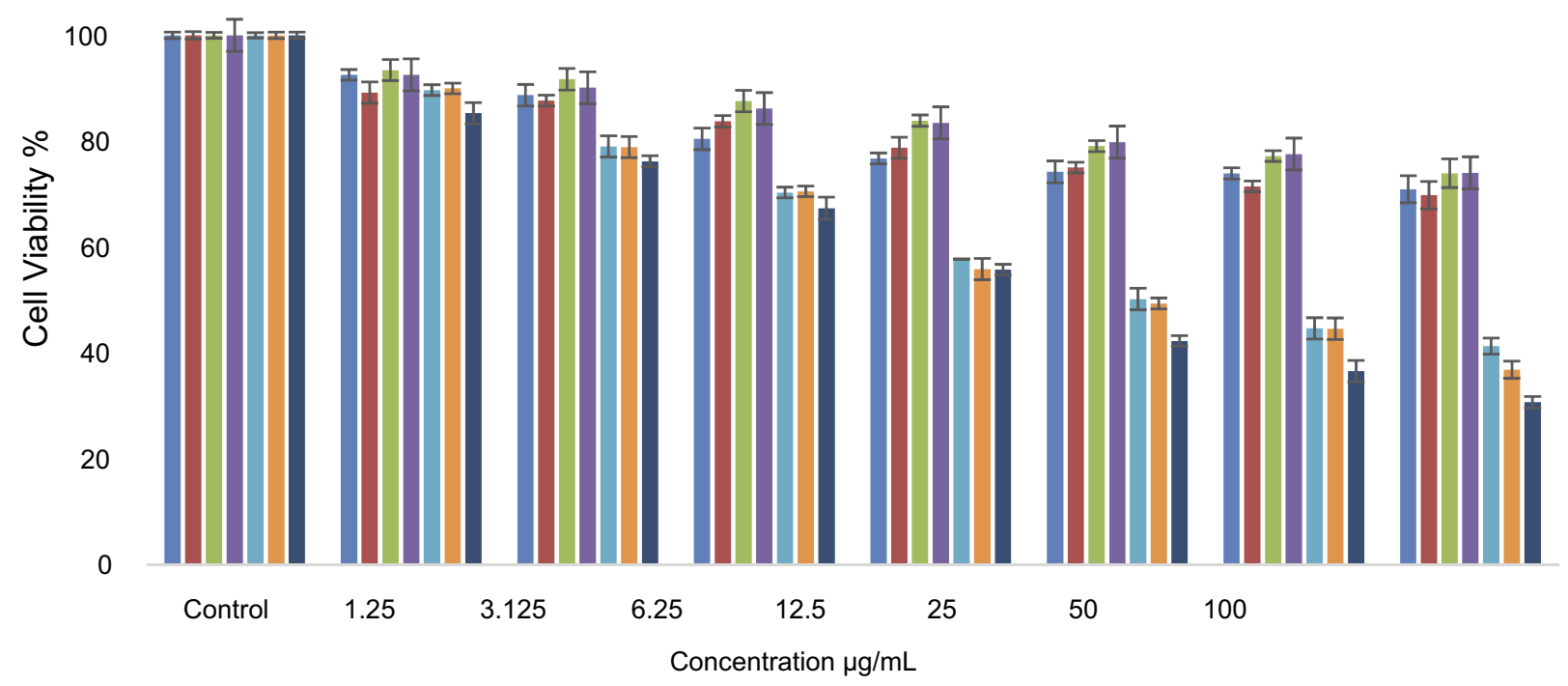

Figure 10 (A) Cytotoxicity assay of iron oxide (Fe), FPEG, FPEG-MLDH, FPEG-ZLDH, 5-Fluorouracil, core-shell nanoparticles, FPVA-FU-MLDH and FPVA-FU-ZLDH against normal 3 T3 cells at 72 hrs. (B) Cytotoxicity assay of iron oxide (Fe), FPEG, FPEG-MLDH, FPEG-ZLDH, 5-fluorouracil, core-shell nanoparticles, FPVA-FU-MLDH and FPVA-FU-ZLDH against HepG2 cells at 72 hrs of incubation.

Cytotoxicity studies on normal fibroblast, 3T3 cells

Cytotoxicity studies were conducted by treating iron oxide (Fe), FPEG, FPEG-MLDH, FPEG-ZLDH, 5-fluorouracil, core-shell nanoparticles; FPVA-FU-MLDH and
FPVA-FU-ZLDH, with normal fibroblast, 3T3 cells. Various gradient concentrations of the samples were incubated for a maximum of $72 \mathrm{hrs}$ with the $3 \mathrm{~T} 3$ cells. Cell viability was determined using the standard MTT assay protocol. Figure 10A shows the percentage cell 
viability of the $3 \mathrm{~T} 3$ cells after $72 \mathrm{hrs}$ incubation for all the samples. All of the samples including iron oxide (Fe), FPEG, FPEG-MLDH, FPEG-ZLDH, 5-fluorouracil, coreshell nanoparticles; FPVA-FU-MLDH and FPVA-FUZLDH were found to be biocompatible and nontoxic, as the cell viability was found to be more than $70 \%$ after $72 \mathrm{hrs}$ incubation. This suggests that the designed anticancer nanoparticle formulation is biocompatible with normal cells and would be very useful for targeting the cancer cells without damaging/harming the normal tissues. The statistics ANOVA revealed that no significant difference was found among the samples groups at individual concentrations using the ANOVA and Duncan's Multiple Range test.

\section{Anticancer action against liver cancer cells, HepG2}

To study the anticancer activity of iron oxide (Fe), FPEG, FPEG-MLDH, FPEG-ZLDH, 5- fluorouracil, core-shell nanoparticles, FPVA-FU-MLDH and FPVA-FU-ZLDH), the samples were treated with liver cancer cells, HepG2 (Figure 10B). Different concentrations of the above samples were incubated with liver cancer cells, HepG2 for $72 \mathrm{hrs}$ and cell viability was determined by the MTT assay protocol. The empty carriers; Fe, FPEG, FPEGMLDH, and FPEG-ZLDH did not show any inhibitory action against liver cancer cells, HepG2. The $\mathrm{IC}_{50}$ of the pure drug, 5-FU against liver cancer cells, HepG2 was found to be $32.73 \mu \mathrm{g} / \mathrm{mL}$. The $\mathrm{IC}_{50}$ of the core-shell nanoparticles; PEG-FU-MLDH and FPVA-FU-ZLDH were found to be $28.88 \mu \mathrm{g} / \mathrm{mL}$ and $20.09 \mu \mathrm{g} / \mathrm{mL}$, respectively. The effective $\mathrm{IC}_{50}$ which is the actual amount of 5$\mathrm{FU}$ present in $\mathrm{IC}_{50}$ of the anticancer nanoparticle was calculated from the percentage of the drug, 5-FU loading which is 68 and $51 \%$ for FPEG-FU-MLDH and FPVAFU-ZLDH, respectively, which were determined using the HPLC analysis. These results suggest that the core-shell nanoparticles of FPEG-FU-MLDH at $28.88 \mu \mathrm{g} / \mathrm{mL}$ and FPVA-FU-ZLDH at $20.09 \mu \mathrm{g} / \mathrm{mL}$ have much better anticancer activity compared to the free drug, 5-fluorouracil. Overall, the study shows that FPVA-FU-ZLDH has better cytotoxicity compared to FPEG-FU-MLDH, even though the drug loading percentage of FPVA-FU-ZLDH is lower, which is only $51 \%$.

Statistical analysis was determined using several softwares; SPSS and ANOVA and Duncan's Multiple
Table 4 The half maximal inhibitory concentration $\left(I_{50}\right)$ value for iron oxide (Fe), FPEG, FPEG-MLDH, FPEG-ZLDH, 5-fluorouracil, core-shell nanoparticles; FPVA-FU-MLDH and FPVA-FUZLDH samples tested on $3 T 3$ and HepG2 cell lines

\begin{tabular}{|l|l|l|}
\hline \multirow{2}{*}{ Nanocomposites } & \multicolumn{2}{|l|}{ IC $\mathbf{5 0}(\mu \mathrm{g} / \mathrm{mL})$} \\
\cline { 2 - 3 } & 3T3 cell lines & HepG2 cell line \\
\hline Fe & N.C & N.C \\
FPEG & N.C & N.C \\
FPEG-MLDH & N.C & N.C \\
FPEG-ZLDH & N.C & N.C \\
5-fluorouracil & N.C & $32.73 \mu \mathrm{g} / \mathrm{mL}$ \\
FPVA-FU-MLDH & N.C & $28.88 \mu \mathrm{g} / \mathrm{mL}$ \\
FPVA-FU-ZLDH & N.C & $20.09 \mu \mathrm{g} / \mathrm{mL}$ \\
\hline
\end{tabular}

Abbreviation: N.C, No cytotoxicity.

Range test. The significant differences were found between the empty carriers, iron oxide (Fe), FPEG, FPEG-MLDH, FPEG-ZLDH, free drug 5-fluorouracil, core-shell nanoparticles; FPEG-FU-MLDH and FPVAFU-ZLDH. The core-shell nanoparticles; FPEG-FUMLDH and FPVA-FU-ZLDH were found significantly different from all the other samples at concentrations of 6.25 to $50 \mu \mathrm{g} / \mathrm{mL}$ with $(P$-values of $<0.5)$. At a concentration of 3.125-100 $\mu \mathrm{g} / \mathrm{mL}$, the samples 5-FU, FPVAFU-MLDH and FPVA-FU-ZLDH were significantly different from the empty carrier. The value was found to be $<0.05$.

The samples; iron oxide (Fe), FPEG, FPEG-MLDH, FPEG-ZLDH, 5-fluorouracil, core-shell nanoparticles; FPVA-FU-MLDH and FPVA-FU-ZLDH showed the anticancer effect towards the cell line is in a dose-dependent manner. The half maximal inhibitory concentration value $\left(\mathrm{IC}_{50}\right)$ of all the samples is given in Table 4. The $\mathrm{IC}_{50}$ values of the nanoparticles determined based on percentage drug loading clearly indicates that the synthesised nanoparticles have a better anticancer effect than the drug in their free forms.

\section{Conclusion}

Magnetite nanoparticles coated with polyethylene glycol/ layered double hydroxide/5-fluorouracil were successfully prepared via co-precipitation method. When $\mathrm{Mg} / \mathrm{Al}-\mathrm{LDH}$ was used as the co-coating agent, the nanocarrier enhanced the percentage of drug loading with narrow size distribution and smaller particle size distribution. The average size distribution of the Mg/Al-LDH co-coated agent was found to be about $69 \mathrm{~nm}$, compared to $82 \mathrm{~nm}$ for the one cocoated with $\mathrm{Zn} / \mathrm{Al}-\mathrm{LDH}$. In addition, the particle size of 
the nanoparticles depends on the type of the nanocarrier; the one co-coated with $\mathrm{Mg} / \mathrm{Al}-\mathrm{LDH}$ is smaller than the one co-coated with $\mathrm{Zn} / \mathrm{Al}-\mathrm{LDH}$. It was also shown that the nanoparticles can retain their superparamagnetic properties; even they were co-coated with 5-FU/LDH. Based on their physico-chemical properties, the synthesized nanoparticles can be further explored to be used as multifunctional nanotheranostics for targeted delivery using an external magnetic field, as hypothermia agent for cancer cells in addition to their chemotherapeutic property.

\section{Acknowledgment}

The authors would like to thank Universiti Putra Malaysia and the Ministry of Higher Education of Malaysia for funding this project under IPB-PUTRA BERIMPAK for MZH. This work was funded by the Universiti Putra Malaysia under IPB-PUTRA BERIMPAK 2019 for MZH. The article processing charge (APC) was funded by the Universiti Putra Malaysia (UPM).

\section{Disclosure}

The authors report no conflicts of interest in this work.

\section{References}

1. Alexis F, Pridgen EM, Langer R, Farokhzad OC. Nanoparticle technologies for cancer therapy. In: Drug Delivery. Berlin: Springer; 2010:55-86.

2. Silva J, Fernandes AR, Baptista PV. Application of nanotechnology in drug delivery. Ali Demir Sezer: IntechOpen; 2019.

3. Yu MK, Jeong YY, Park J, et al. Drug-loaded superparamagnetic iron oxide nanoparticles for combined cancer imaging and therapy in vivo. Angew Chem Int Ed. 2008;47:5362-5365. doi:10.1002/anie.v47:29

4. Blanco E, Hsiao A, Mann AP, Landry MG, Meric-Bernstam F, Ferrari M. Nanomedicine in cancer therapy: innovative trends and prospects. Cancer Sci. 2011;102:1247-1252. doi:10.1111/j.1349-7006.2011.01930.x

5. Peer D, Karp JM, Hong S, Farokhzad OC, Margalit R, Langer R. Nanocarriers as an emerging platform for cancer therapy. Nat Nanotechnol. 2007;2:751. doi:10.1038/nnano.2007.387

6. Misra R, Acharya S, Sahoo SK. Cancer nanotechnology: application of nanotechnology in cancer therapy. Drug Discov Today. 2010;15:842-850. doi:10.1016/j.drudis.2010.08.006

7. Baptista PV. Cancer nanotechnology-prospects for cancer diagnostics and therapy. Curr Cancer Ther Rev. 2009;5:80-88. doi:10.2174/ 157339409788166733

8. Nicolini A, Carpi A, Ferrari P, Mario Biava P, Rossi G. Immunotherapy and hormone-therapy in metastatic breast cancer: a review and an update. Curr Drug Targets. 2016;17:1127-1139. doi: $10.2174 / 1389450117666160201114752$

9. HUSSEIN-AL-ALI SH, ARULSELVAN P, HUSSEIN MZ, et al. Characterization, controlled release and cytotoxic effect of anthranilic acid-loaded chitosan and polyethylene glycol-magnetic nanoparticles on murine macrophage raw 264.7 cells. Nano. 2014;09:1450016. doi: $10.1142 / \mathrm{S} 1793292014500167$

10. Hussein-Al-Ali SH, El Zowalaty ME, Hussein MZ, Ismail M, Dorniani D, Webster TJ. Novel kojic acid-polymer-based magnetic nanocomposites for medical applications. Int J Nanomedicine. 2014;9:351-362.
11. Barrett AP. A long-term prospective clinical study of oral complications during conventional chemotherapy for acute leukemia. Oral Surg Oral Med Oral Pathol. 1987;63:313-316. doi:10.1016/0030-4220(87)90196-4

12. Akbulut M, D'Addio SM, Gindy ME, Prud'homme RK. Novel methods of targeted drug delivery: the potential of multifunctional nanoparticles. Expert Rev Clin Pharmacol. 2009;2:265-282. doi:10.1586/ecp.09.4

13. Chari RVJ. Targeted cancer therapy: conferring specificity to cytotoxic drugs. Acc Chem Res. 2007;41:98-107. doi:10.1021/ar700108g

14. Estelrich J, Escribano E, Queralt J, Busquets MA. Iron oxide nanoparticles for magnetically-guided and magnetically-responsive drug delivery. Int $J$ Mol Sci. 2015;16:8070-8101. doi:10.3390/ ijms 16048070

15. Lee H, Shao H, Huang Y, Kwak B. Synthesis of MRI contrast agent by coating superparamagnetic iron oxide with chitosan. IEEE Trans Magn. 2005;41:4102-4104. doi:10.1109/TMAG.2005.855338

16. Bárcena C, Sra AK, Gao J. Applications of magnetic nanoparticles in biomedicine. In: Nanoscale Magnetic Materials and Applications. Boston, MA: Springer; 2009:591-626.

17. Usman MS, Hussein MZ, Fakurazi S, Ahmad Saad FF. Gadoliniumbased layered double hydroxide and graphene oxide nano-carriers for magnetic resonance imaging and drug delivery. Chem Cent J. 2017;11. doi:10.1186/s13065-017-0351-8

18. Sani Usman M, Hussein M, Fakurazi S, Masarudin M, Ahmad Saad F. Gadolinium-doped gallic acid-zinc/aluminium-layered double hydroxide/gold theranostic nanoparticles for a bimodal magnetic resonance imaging and drug delivery system. Nanomaterials. 2017:7:244. doi:10.3390/nano7120458

19. Usman MS, Hussein MZ, Kura AU, Fakurazi S, Masarudin MJ, Saad FFA. Synthesis and characterization of protocatechuic acid-loaded gadoliniumlayered double hydroxide and gold nanocomposite for theranostic application. Appl Nanosci. 2018;8:973-986. doi:10.1007/s13204-018-0752-6

20. Sharma N, Agarwal G, Rana AC, Bhat ZALI. A review : transdermal drug delivery system: a tool for novel drug delivery system. Int J Drug Dev Res. 2011;3:70-84. Covered in Official Product of Elsevier, The Netherlands (C 2010 IJDDR. Available from: http://www.ijddr.in

21. Park K. Controlled drug delivery systems: past forward and future back. J Control Release. 2014;190:3-8. doi:10.1016/j.jconrel.2014.03.054

22. Sachan R, Bajpai M. Review article transdermal drug delivery system: a review. International Journal of Research and Development in Pharmacy and Life Sciences. 2013;3:748-765.

23. Bhatia S. Natural Polymer Drug Delivery Systems: Nanoparticles, Plants, and Algae; India: Springer; 2016. ISBN 9783319411293.

24. Suresh Rewar A. Review article review on: intraoccular drug delivery system. International Journal of Research and Development in Pharmacy and Life Sciences. 2014;3:1236-1243.

25. Gandhi M, Chaudhari R, Kulkarni N, Bhusare S, Kare P. Review article on pulsatile drug delivery system. Int J Pharm Sci Rev Res. 2014;26:251-255.

26. Ealias AM, Saravanakumar MP. A review on the classification, characterisation, synthesis of nanoparticles and their application. India. IOP Conference Series: Materials Science and Engineering. Vol. 263; 2017.

27. Wang JJ, Zeng ZW, Xiao RZ, et al. Recent advances of chitosan nanoparticles as drug carriers. Int J Nanomedicine. 2011;6:765-774. doi:10.2147/IJN.S25646

28. Zhou L, Yuan J, Wei Y. Core-shell structural iron oxide hybrid nanoparticles: from controlled synthesis to biomedical applications. J Mater Chem. 2011;21:2823-2840. doi:10.1039/C0JM02172E

29. Chatterjee K, Sarkar S, Rao KJ, Paria S. Core/shell nanoparticles in biomedical applications. Adv Colloid Interface Sci. 2014;209:8-39. doi:10.1016/j.cis.2013.12.008

30. Dorniani D, Kura AU, Hussein-Al-Ali SH, et al. In vitro sustained release study of gallic acid coated with magnetite-PEG and magnetite-PVA for drug delivery system. Sci World J. 2014;2014:1-11. doi:10.1155/2014/ 416354 
31. Ochekpe NA, Olorunfemi PO, Ngwuluka NC. Nanotechnology and drug delivery part 2: nanostructures for drug delivery. Trop J Pharm Res. 2009;8(3):275-287.

32. Mahmoudi M, Simchi A, Imani M, Hafeli UO. Superparamagnetic iron oxide nanoparticles with rigid cross-linked polyethylene glycol fumarate coating for application in imaging and drug delivery. J Phys Chem C. 2009;113:8124-8131. doi:10.1021/jp900798r

33. Nadeem M, Ahmad M, Akhtar MS, et al. Magnetic properties of polyvinyl alcohol and doxorubicine loaded iron oxide nanoparticles for anticancer drug delivery applications. PLoS One. 2016;11:1-12. doi:10.1371/journal.pone.0158084

34. Dorniani D, Kura AU, Bin Hussein MZ, Fakurazi S, Shaari AH, Ahmad Z. Controlled-release formulation of perindopril erbumine loaded PEGcoated magnetite nanoparticles for biomedical applications. J Mater Sci. 2014;49:8487-8497. doi:10.1007/s10853-014-8559-7

35. Cole AJ, David AE, Wang J, Galbán CJ, Hill HL, Yang VC. Polyethylene glycol modified, cross-linked starch-coated iron oxide nanoparticles for enhanced magnetic tumor targeting. Biomaterials. 2011;32:2183-2193. doi:10.1016/j.biomaterials.2010.11.040

36. Kuang Y, Zhao L, Zhang S, Zhang F, Dong $\mathrm{M}$, Xu S. Morphologies, preparations and applications of layered double hydroxide micro-/nanostructures. Materials. 2010;3:5220-5235. doi:10.3390/ma3125220

37. Singh P, Pandit S, Mokkapati V, Garg A, Ravikumar V, Mijakovic I. Gold nanoparticles in diagnostics and therapeutics for human cancer. Int J Mol Sci. 2018;19:1979. doi:10.3390/ijms19071979

38. Champion JA, Katare YK, Mitragotri S. Particle shape: a new design parameter for micro- and nanoscale drug delivery carriers. J Control Release. 2007;121:3-9. doi:10.1016/j.jconrel.2007.03.022

39. Han J, Xu X, Rao X, Wei M, Evans DG, Duan X. Layer-by-layer assembly of layered double hydroxide/cobalt phthalocyanine ultrathin film and its application for sensors. J Mater Chem. 2011;21:21262130. doi:10.1039/C0JM02430A

40. Fan G, Li F, Evans DG, Duan X. Catalytic applications of layered double hydroxides: recent advances and perspectives. Chem Soc Rev. 2014;43:7040-7066. doi:10.1039/C4CS00160E

41. Costa FR, Wagenknecht U, Heinrich G, Jehnichen D, Manhique A, Aus- DA. Layered double hydroxides: noble materials for the development of multi-functional nanohybrids. 2005;27-33.

42. Nalawade P, Aware B, Kadam VJ, Hirlekar RS. Layered double hydroxides: a review.

43. Guo Y, Zhang Y, Ma J, et al. Light/magnetic hyperthermia triggered drug released from multi-functional thermo-sensitive magnetoliposomes for precise cancer synergetic theranostics. J Control Release. 2018;272:145-158. doi:10.1016/j.jconrel.2017.04.028

44. Sydow S, de Cassan D, Hänsch R, et al. Layer-by-layer deposition of chitosan nanoparticles as drug-release coatings for PCL nanofibers. Biomater Sci. 2019;7:233-246. doi:10.1039/C8BM00657A

45. Adeyemi OS, Sulaiman FA. Evaluation of metal nanoparticles for drug delivery systems. J Biomed Res. 2015;29:145.

46. Sipiczki M. Functional materials-syntheses, characterisation and catalytic applications. University of Szeged: 2013.

47. Zhang X, Chen Q, Guo L, Huang H, Ruan C. Effects of varying particle sizes and different types of LDH-modified anthracite in simulated test columns for phosphorous removal. Int J Environ Res Public Health. 2015;12:6788-6800. doi:10.3390/ijerph120606788

48. Abdollah SM, Fereshteh F, Nazanin F. Synthesis and modification of iron oxide nanoparticles (magnetite) for biomedical applications. Res J Biotechnol. 2017;12:87-95.

49. Li L, Feng Y, Li Y, Zhao W, Shi J. Fe3O4 core/layered double hydroxide shell nanocomposite: versatile magnetic matrix for anionic functional materials. Angew Chem Int Ed. 2009;48:5888-5892. doi:10.1002/anie.v48:32

50. Xianghong Peng HC, Huang J, Dong M, Shin HM. Targeted magnetic iron oxide nanoparticles for tumor imaging and therapy - from theory to applications. Int J Nanomedicine. 2011;3:311-321.
51. Bucak S, Yavuzturk B, Demir A. Magnetic nanoparticles: synthesis, surface modifications and application in drug delivery. Recent Adv Novel Drug Carrier Syst. 2012.

52. Hoskins C. The use of iron oxide nanoparticles for pancreatic cancer therapy. J Nanomed Res. 2014;1:1-12. doi:10.15406/jnmr

53. Laurent S, Forge D, Port M, et al. Magnetic iron oxide nanoparticles: synthesis, stabilization, vectorization, physicochemical characterizations, and biological applications. Chem Rev. 2008;108:2064-2110. doi: $10.1021 / \mathrm{cr} 068445 \mathrm{e}$

54. Laurent S, Mahmoudi M. Superparamagnetic iron oxide nanoparticles: promises for diagnosis and treatment of cancer. Int $\mathrm{J} \mathrm{Mol}$ Epidemiol Genet. 2011;2:367-390.

55. Zhang H, Pan D, Duan X. Synthesis, characterization, and magnetically controlled release behavior of novel core-shell structural magnetic ibuprofen-intercalated $1 \mathrm{dh}$ nanohybrids. J Phys Chem C. 2009;113:12140-12148. doi:10.1021/jp901060v

56. Gupta AK, Gupta M. Synthesis and surface engineering of iron oxide nanoparticles for biomedical applications. Biomaterials. 2005;26:3995-4021. doi:10.1016/j.biomaterials.2004.10.012

57. Xu JK, Zhang FF, Sun JJ, Sheng J, Wang F, Sun M. Bio and nanomaterials based on Fe3O4. Molecules. 2014;19:21506-21528. doi:10.3390/molecules 190811211

58. Zarnegar Z, Safari J. Catalytic activity of $\mathrm{Cu}$ nanoparticles supported on Fe3O4-polyethylene glycol nanocomposites for the synthesis of substituted imidazoles. New J Chem. 2014;38:4555-4565. doi:10.1039/C4NJ00645C

59. Gupta A, Tiwari G, Tiwari R, Srivastava R, Rai AK. Enteric coated HPMC capsules plugged with 5-FU loaded microsponges: a potential approach for treatment of colon cancer. Braz J Pharm Sci. 2015;51:591-606. doi:10.1590/S1984-82502015000300011

60. Zhu F, Shi Z, Qin C, et al. Therapeutic target database update 2012: a resource for facilitating target-oriented drug discovery. Nucleic Acids Res. 2011;40:D1128-D1136. doi:10.1093/nar/gkr797

61. Venkatesh Gavini M, Srinivasa Murthy PKK. Formulation and invitro evaluation of nanoparticulate drug delivery system loaded with 5fluorouracil formulation and invitro evaluation of nanoparticulate drug delivery. Res J Pharm Dosage Forms Technol. 2015;6(4):243248 .

62. Li M, Deng L, Li J, et al. Actively targeted magnetothermally responsive nanocarriers/doxorubicin for thermochemotherapy of hepatoma. ACS Appl Mater Interfaces. 2018;10:41107-41117. doi:10.1021/acsami.8b14972

63. Clares B, Biedma-Ortiz RA, Sáez-Fernández E, et al. Nano-engineering of 5-fluorouracil-loaded magnetoliposomes for combined hyperthermia and chemotherapy against colon cancer. Eur J Pharm Biopharm. 2013;85:329-338. doi:10.1016/j.ejpb.2013.01.028

64. Zhu L, Shen GJ, Ding SQ, Hua X. Determination of 5-fluorouracil in 5-fluorouracil injection and human serum by HPLC. J Food Drug Anal. 2012;20:947-950.

65. Saifullah B, El Zowalaty ME, Arulselvan P, et al. Antimycobacterial, antimicrobial, and biocompatibility properties of para-aminosalicylic acid with zinc layered hydroxide and $\mathrm{Zn} / \mathrm{Al}$ layered double hydroxide nanocomposites. Drug Des Devel Ther. 2014;8:1029-1036. doi:10.2147/DDDT. S66007

66. Saifullah B, Arulselvan P, El Zowalaty ME, et al. Development of a biocompatible nanodelivery system for tuberculosis drugs based on isoniazid-Mg/Al layered double hydroxide. Int $J$ Nanomedicine. 2014;9:4749

67. Dorniani D, Bin Hussein MZ, Kura AU, Fakurazi S, Shaari AH, Ahmad Z. Preparation and characterization of 6-mercaptopurinecoated magnetite nanoparticles as a drug delivery system. Drug Des Devel Ther. 2013;7:1015. doi:10.2147/DDDT.S43035

68. Dorniani D, Bin Hussein MZ, Kura AU, Fakurazi S, Shaari AH, Ahmad Z. Sustained release of prindopril erbumine from its chitosan-coated magnetic nanoparticles for biomedical applications. Int $J$ Mol Sci. 2013;14:23639-23653. doi:10.3390/ijms141223639 
69. Kievit FM, Zhang M. Surface engineering of iron oxide nanoparticles for targeted cancer therapy. Acc Chem Res. 2011;44:853-862. doi:10.1021/ar2000277

70. Dorniani D, Bin Hussein MZ, Kura AU, Fakurazi S, Shaari AH, Ahmad Z. Preparation of Fe3O4 magnetic nanoparticles coated with gallic acid for drug delivery. Int $J$ Nanomedicine. 2012;7:5745. doi:10.2147/IJN.S30631

71. Giustini AJ, Petryk AA, Cassim SM, Tate JA, Baker I, Hoopes PJ. Magnetic nanoparticle hyperthermia in cancer treatment. Nano Life. 2010;1:17-32. doi:10.1142/S1793984410000067

72. Bañobre-López M, Teijeiro A, Rivas J. Magnetic nanoparticle-based hyperthermia for cancer treatment. Rep Pract Oncol Radiother. 2013;18:397-400. doi:10.1016/j.rpor.2013.09.011

73. Park JY, Daksha P, Lee GH, Woo S, Chang Y. Highly water-dispersible PEG surface modified ultra small superparamagnetic iron oxide nanoparticles useful for target-specific biomedical applications. Nanotechnology. 2008;19:365603. doi:10.1088/0957-4484/19/36/365603

74. Naseroleslami M, Parivar K, Khoei S, Aboutaleb N. Magnetic resonance imaging of human-derived amniotic membrane stem cells using PEGylated superparamagnetic iron oxide nanoparticles. Cell J. 2016;18:332-339.

75. Moisescu-Goia C, Muresan-Pop M, Simon V. New solid state forms of antineoplastic 5-fluorouracil with anthelmintic piperazine. $\mathrm{J} \mathrm{Mol}$ Struct. 2017;1150:37-43. doi:10.1016/j.molstruc.2017.08.076
76. Ikhsani IY, Santosa SJ, Rusdiarso B. Comparative study of Ni-Zn LHS and Mg-Al LDH adsorbents of navy blue and yellow F3G dye. Indones J Chem. 2016;16:36-44. doi:10.22146/ijc.21175

77. Kura AU, Hussein-Al-Ali SH, Hussein MZ, Fakurazi S. Preparation of Tween $80-\mathrm{Zn}$ /Al-levodopa-layered double hydroxides nanocomposite for drug delivery system. Sci World J. 2014;2014:1-10. doi:10.1155/2014/ 104246

78. Yang B, Kallio H. Composition and physiological effects of sea buckthorn (Hippophae) lipids. Trends Food Sci Technol. 2002;13:160-167. doi:10.1016/S0924-2244(02)00136-X

79. Lv F, Wu Y, Zhang Y, Shang J, Chu PK. Structure and magnetic properties of soft organic ZnAl-LDH/polyimide electromagnetic shielding composites. J Mater Sci. 2012;47:2033-2039. doi:10.1007/s10853-011-6003-9

80. Kimura T, Ago H, Tobita M, Ohshima S, Kyotani M, Yumura M. Polymer composites of carbon nanotubes aligned by a magnetic field. Adv Mater. 2002;14:1380-1383. doi:10.1002/1521-4095 (20021002)14:19<1380::AID-ADMA1380>3.0.CO;2-V

81. Costa FR, Leuteritz A, Wagenknecht U, et al. Alkyl sulfonate modified LDH: effect of alkyl chain length on intercalation behavior, particle morphology and thermal stability. Appl Clay Sci. 2009;44:7-14. doi:10.1016/j.clay.2008.12.020
International Journal of Nanomedicine

\section{Publish your work in this journal}

The International Journal of Nanomedicine is an international, peerreviewed journal focusing on the application of nanotechnology in diagnostics, therapeutics, and drug delivery systems throughout the biomedical field. This journal is indexed on PubMed Central, MedLine, CAS, SciSearch ${ }^{\mathbb{R}}$, Current Contents ${ }^{\mathbb{R}} /$ Clinical Medicine,

\section{Dovepress}

Journal Citation Reports/Science Edition, EMBase, Scopus and the Elsevier Bibliographic databases. The manuscript management system is completely online and includes a very quick and fair peer-review system, which is all easy to use. Visit http://www.dovepress.com/ testimonials.php to read real quotes from published authors. 